Article

\title{
Versatile Voltage-Mode Biquadratic Filter and Quadrature Oscillator Using Four OTAs and Two Grounded Capacitors
}

\author{
San-Fu Wang ${ }^{1}$, Hua-Pin Chen ${ }^{2, *(\mathbb{D})}$, Yitsen $\mathrm{Ku}^{3}$ and Chia-Ling Lee ${ }^{2}$ \\ 1 Department of Electronic Engineering, National Chin-Yi University of Technology, Taichung 41170, Taiwan; \\ sf_wang@ncut.edu.tw \\ 2 Department of Electronic Engineering, Ming Chi University of Technology, New Taipei 24301, Taiwan; \\ m07158003@o365.mcut.edu.tw \\ 3 Department of Electrical Engineering, California State University Fullerton, Fullerton, CA 92831, USA; \\ joshuaku@fullerton.edu \\ * Correspondence: hpchen@mail.mcut.edu.tw; Tel.: +886-2-2908-9899; Fax: +886-2-2908-5247
}

Received: 24 July 2020; Accepted: 9 September 2020; Published: 11 September 2020

\begin{abstract}
This article presents a versatile voltage-mode (VM) biquad filter with independently electronic tunability. The proposed structure using one dual-output operational transconductance amplifier, three single-output operational transconductance amplifiers (OTAs) and two grounded capacitors was explored to derive a new VM quadrature oscillator with the independent control of the oscillation frequency and the oscillation condition. The proposed versatile VM biquad filter achieves nearly all of the main advantages: (i) simultaneous realizations of band-reject, band-pass, and low-pass from the same architecture, (ii) multiple-input and multiple-output functions, (iii) independent electronic adjustability of quality factor and resonant angular frequency, (iv) no resistor needed, (v) all input terminals with cascade functions, (vi) no additional inverting amplifier for input signals, (vii) using only grounded capacitors, and (viii) easy to implement a VM quadrature oscillator with independent electronically controlled oscillation frequency and oscillation condition. The proposed versatile VM biquad filter employs only four OTAs and two grounded capacitors. The active components of the proposed VM biquad filter are one less than that of recent reports. The proposed circuit also brings versatility and simplicity to the design of VM biquad filters and VM quadrature oscillators. Filters and oscillators with less active and passive components have the advantages of low cost, low power dissipation, low circuit complexity, and low noise. Commercially available integrated circuit LT1228 and discrete components can be used to implement the proposed OTA-based circuits. The simulation and experiment results validated the theoretical analysis.
\end{abstract}

Keywords: voltage-mode circuit; operational transconductance amplifier; quadrature oscillator; analog filter

\section{Introduction}

In various electronic and communication systems, analog filters and oscillators are basic components. Their applications have been presented in the open literature [1-5]. For example, Figure 1 shows the triple-section crossover network for high-fidelity loudspeakers [4], and the principle of the dual phase sensitive detection (PSD) system [5]. When designing voltage-mode (VM) active biquads and oscillators, many circuits have been proposed that have good applications and advantages by using different active components [1-49]. The applications and advantages in designing electronically tunable operational transconductance amplifier-capacitor (OTA-C) filters also received considerable attention [16,34-40,42-49]. In analog integrated circuit (IC) designs, electronically adjustable circuits 
have become the focus of attention, because in the practice of ICs, the tolerances of electronic components in implementation are too high, so fine-tuning must be performed after manufacturing. Therefore, the single-output operational transconductance amplifier (OTA) is very suitable for the design of electronic adjustable circuits, because the transconductance gain $\left(\mathrm{g}_{\mathrm{m}}\right)$ of OTA can be regulated by an outside direct current (DC) bias current, $\mathrm{I}_{\mathrm{B}}$. The high-input impedance VM biquads have also been extensively investigated, because it can be easily connected in series to form a high-order filter. Hence, many VM biquads with high-input impedances have been studied [6,7,10,38-49].

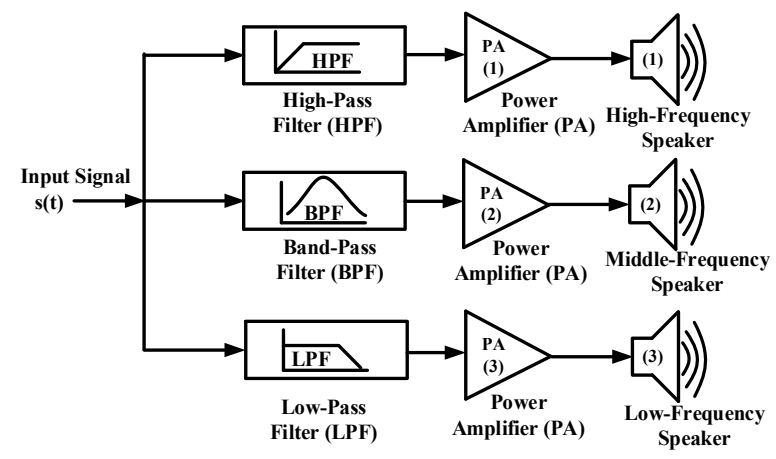

(a)

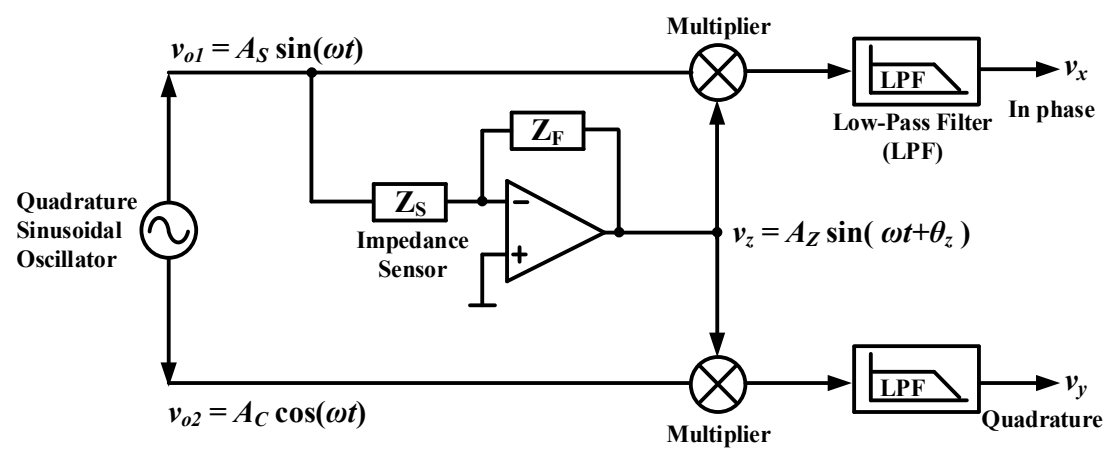

(b)

Figure 1. Basic block diagram of the three-way high-fidelity loudspeaker crossover network and phase sensitive detection (PSD) system. (a) Triple-section crossover network for high-fidelity loudspeakers [4]; and (b) the PSD system [5].

On the basis of the input signals, the VM universal biquads with different filtering functions are obtained, which provide the low-pass (LP), high-pass (HP), band-pass (BP), band-reject (BR), and all-pass (AP) filtering functions in one circuit architecture. The advantage of the VM multifunction biquad filter is that it can simultaneously form BP, LP, HP and/or BR outputs in the same architecture, which can improve the flexibility and versatility of practical applications. Although three electronically tunable VM biquads based on OTAs have been recently proposed [45-47], these proposed circuits cannot realize BR, BP and LP filtering responses simultaneously. In [48,49], two circuit topologies were proposed in 2019 that operated in a versatile VM biquad filter with five OTAs and two grounded capacitors. Both circuits in $[48,49]$ can achieve five standard filter responses, and can independently control the parameters quality factor $(\mathrm{Q})$ and resonance angular frequency $\left(\omega_{\mathrm{o}}\right)$. The circuits have two more important advantages, that is, they can simultaneously realize BR, BP and LP biquad filters in the same architecture, and they can implement a VM quadrature oscillator with independently electronically controlled condition of oscillation (CO) and frequency of oscillation (FO).

This article proposes a new versatile high-input impedance electronic controllable VM biquad filter. The circuit consists of one dual-output operational transconductance amplifier (DO-OTA), three OTAs and two grounded capacitors. The proposed circuit can independently and electronically 
control the parameters of $\omega_{\mathrm{o}}$ and Q. The proposed versatile VM biquad filter simultaneously has the following eight performance characteristics without trade-offs: (i) employing one DO-OTA, three OTAs and two grounded capacitors without any resistors, (ii) multiple-input and multiple-output functions, (iii) implementing BR, BP and LP biquadratic filtering functions simultaneously with three output terminals, (iv) providing all five standard biquadratic filtering functions with a single-output terminal, (v) tuning $\omega_{\mathrm{o}}$ and $\mathrm{Q}$ independently and electronically, (vi) having high-input impedance terminals, (vii) no extra inverting amplifiers for special input signals, and (viii) easily a realizing VM quadrature oscillator with the electronic and independent control of $\mathrm{CO}$ and FO. Table 1 lists the property comparisons between the proposed circuit and the previous VM biquads. From Table 1, the proposed circuit satisfies all the important properties mentioned above. To the best knowledge of authors, all these properties cannot be achieved simultaneously by any of the earlier known VM biquads [6-11,24-26,34-38,41-49]. With respect to the VM six-OTA biquads in [45,46], the proposed circuit uses two less active components and obtains simultaneous BR, BP and LP biquadratic filtering functions in the same architecture. With respect to the VM five-OTA biquads in [47-49], the proposed circuit uses one less active component and the filter parameters $\omega_{0}$ and $Q$ can still be independent and electronically adjusted. Filters and oscillators using less active and passive components have the advantages of low cost, low power dissipation, low circuit complexity, and low noise.

This article is organized as follows: Section 2 presents the proposed versatile VM biquad filter with independently electronic tunability and the proposed VM quadrature oscillator with the independent and electronic control of $\mathrm{CO}$ and FO. Section 3 performs the parasitic and non-ideality analysis for the proposed filter. Section 4 emphasizes and evaluates the respective simulation and measured results obtained employing Cadence OrCAD PSpice software and the LT1228 ICs with discrete components. The experimental test bench is also described in Section 4. Finally, Section 5 is the conclusions. 
Table 1. Comparisons of the proposed versatile voltage-mode (VM) biquad filter with previous report circuits.

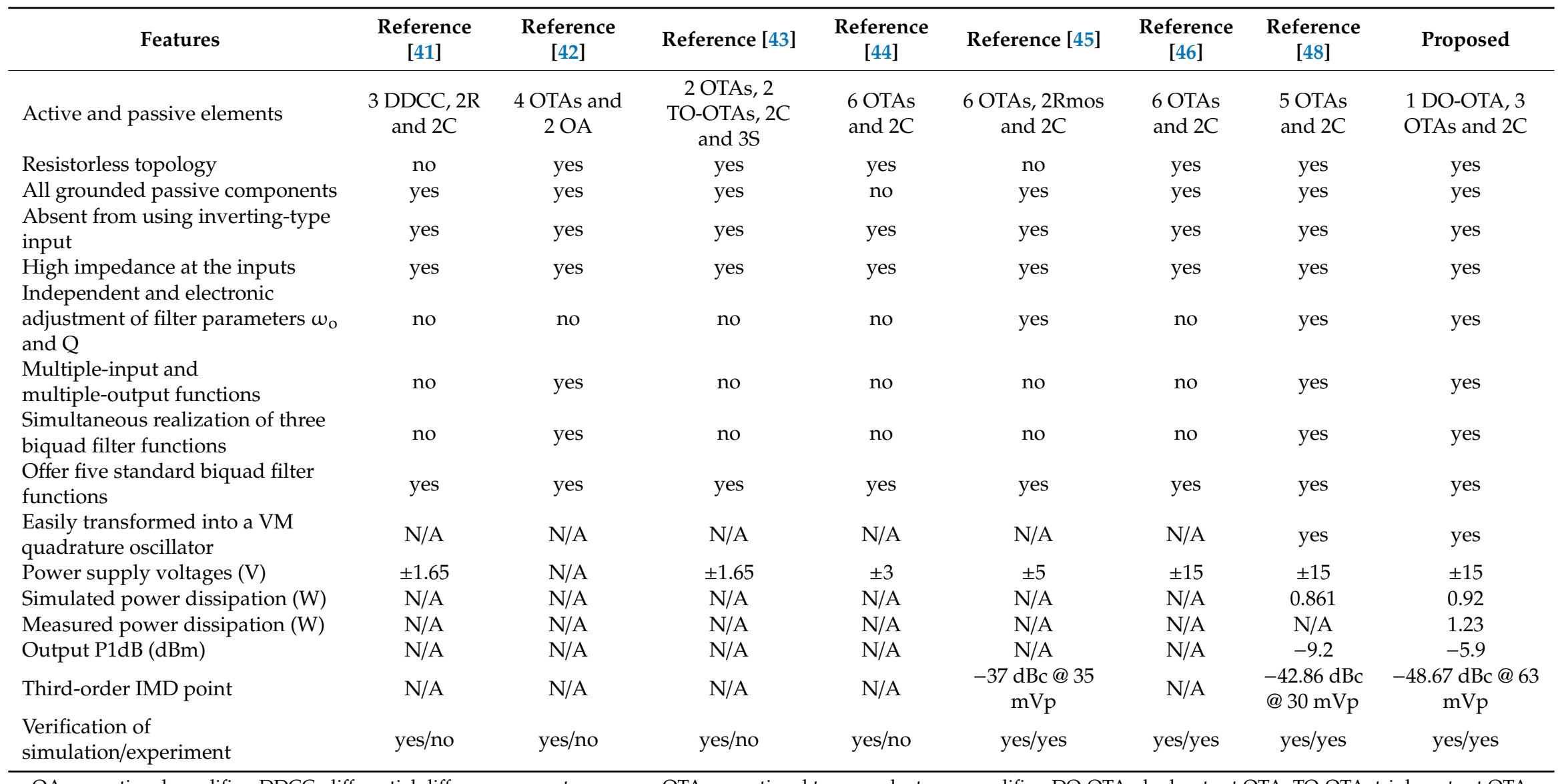

OA: operational amplifier; DDCC: differential difference current conveyor; OTA: operational transconductance amplifier; DO-OTA: dual-output OTA; TO-OTA: triple-output OTA;

C: capacitor; S: switch; R: resistor; Rmos: metal oxide semiconductor resistor; IMD: intermodulation distortion; P1dB: 1-dB power gain compression point; $\omega_{\mathrm{o}}$ : resonance angular frequency;

Q: quality factor; N/A—not available or not tested. 


\section{Circuit Descriptions}

\subsection{Proposed Versatile VM Biquad Filter}

OTA is an active component available on the market, and is frequently utilized in the application and design of electronic controllable circuits. The symbol of OTA is shown in Figure 2a, which is a single current output OTA. Figure $2 b$ shows the symbol for a DO-OTA, which is a dual current output OTA. The dual current outputs of the OTA can be characterized by $\mathrm{I}_{\mathrm{O}}= \pm \mathrm{g}_{\mathrm{m}}\left(\mathrm{V}_{+}-\mathrm{V}_{-}\right)$[34]. The symbol \pm shows the polarity of the current output.

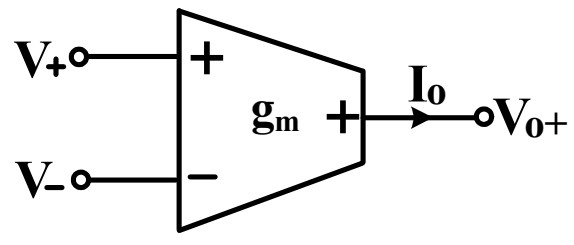

(a)

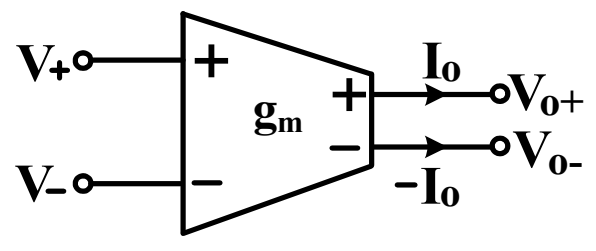

(b)

Figure 2. Symbols for operational transconductance amplifier (OTA) and dual-output operational transconductance amplifier (DO-OTA). (a) OTA. (b) DO-OTA.

Figure 3 shows the proposed versatile VM OTA-C biquad. It employs one DO-OTA, three OTAs and two grounded capacitors with four input signals and three output signals. The routine analysis of the circuit in Figure 3 can derive the following three output voltage signals:

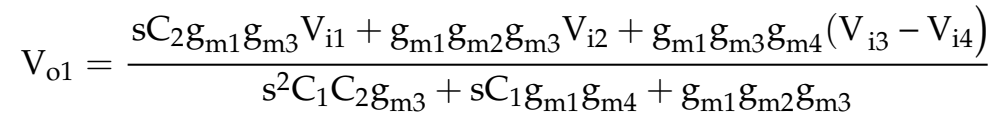

$$
\begin{aligned}
& V_{\mathrm{o} 2}=\frac{\left(\mathrm{sC}_{1} \mathrm{~g}_{\mathrm{m} 1} \mathrm{~g}_{\mathrm{m} 4}+\mathrm{g}_{\mathrm{m} 1} \mathrm{~g}_{\mathrm{m} 2} \mathrm{~g}_{\mathrm{m} 3}\right) \mathrm{V}_{\mathrm{i} 1}-\mathrm{sC}_{1} \mathrm{~g}_{\mathrm{m} 2} \mathrm{~g}_{\mathrm{m} 3} \mathrm{~V}_{\mathrm{i} 2}-\mathrm{sC}_{1} \mathrm{~g}_{\mathrm{m} 3} \mathrm{~g}_{\mathrm{m} 4}\left(\mathrm{~V}_{\mathrm{i} 3}-\mathrm{V}_{\mathrm{i} 4}\right)}{\mathrm{s}^{2} \mathrm{C}_{1} \mathrm{C}_{2} \mathrm{~g}_{\mathrm{m} 3}+\mathrm{sC}_{1} \mathrm{~g}_{\mathrm{m} 1} \mathrm{~g}_{\mathrm{m} 4}+\mathrm{g}_{\mathrm{m} 1} \mathrm{~g}_{\mathrm{m} 2} \mathrm{~g}_{\mathrm{m} 3}} \\
& V_{\mathrm{o} 3}=\frac{-\mathrm{s}^{2} \mathrm{C}_{1} \mathrm{C}_{2} \mathrm{~g}_{\mathrm{m} 1} \mathrm{~V}_{\mathrm{i} 1}-\mathrm{sC}_{1} \mathrm{~g}_{\mathrm{m} 1} \mathrm{~g}_{\mathrm{m} 2} \mathrm{~V}_{\mathrm{i} 2}+\left(\mathrm{s}^{2} \mathrm{C}_{1} \mathrm{C}_{2} \mathrm{~g}_{\mathrm{m} 3}+\mathrm{g}_{\mathrm{m} 1} \mathrm{~g}_{\mathrm{m} 2} \mathrm{~g}_{\mathrm{m} 3}\right) \mathrm{V}_{\mathrm{i} 3}+\mathrm{sC}_{1} \mathrm{~g}_{\mathrm{m} 1} \mathrm{~g}_{\mathrm{m} 4} \mathrm{~V}_{\mathrm{i} 4}}{\mathrm{~s}^{2} \mathrm{C}_{1} \mathrm{C}_{2} \mathrm{~g}_{\mathrm{m} 3}+\mathrm{sC}_{1} \mathrm{~g}_{\mathrm{m} 1} \mathrm{~g}_{\mathrm{m} 4}+\mathrm{g}_{\mathrm{m} 1} \mathrm{~g}_{\mathrm{m} 2} \mathrm{~g}_{\mathrm{m} 3}}
\end{aligned}
$$

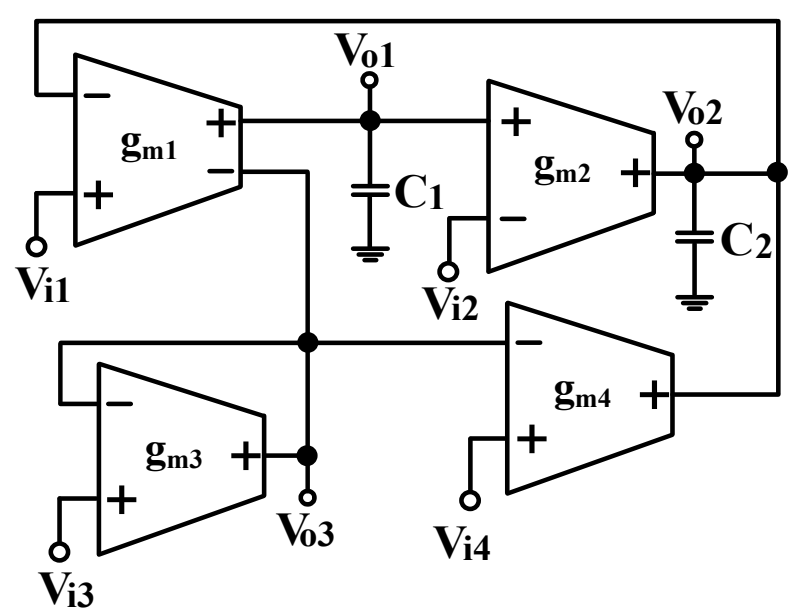

Figure 3. Proposed versatile VM biquad.

From Equations (1)-(3), there are two different possibilities to realize the VM multifunction biquad according to input and output conditions as follows. 
Case I: If $\mathrm{V}_{\mathrm{i} 1}=\mathrm{V}_{\mathrm{i} 2}=\mathrm{V}_{\mathrm{i} 4}=0$ (grounded) and $\mathrm{V}_{\mathrm{i} 3}=$ input voltage signal $\left(\mathrm{V}_{\mathrm{in}}\right)$, then three biquadratic filtering functions can be obtained as shown in Equations (4)-(6):

$$
\begin{aligned}
& \frac{V_{\mathrm{o} 1}}{V_{\text {in }}}=\frac{g_{\mathrm{m} 1} g_{\mathrm{m} 3} g_{\mathrm{m} 4}}{\mathrm{~s}^{2} \mathrm{C}_{1} \mathrm{C}_{2} g_{\mathrm{m} 3}+\mathrm{sC}_{1} \mathrm{~g}_{\mathrm{m} 1} \mathrm{~g}_{\mathrm{m} 4}+\mathrm{g}_{\mathrm{m} 1} \mathrm{~g}_{\mathrm{m} 2} \mathrm{~g}_{\mathrm{m} 3}} \\
& \frac{V_{o 2}}{V_{\text {in }}}=\frac{-\mathrm{sC}_{1} g_{\mathrm{m} 3} g_{\mathrm{m} 4}}{\mathrm{~s}^{2} \mathrm{C}_{1} \mathrm{C}_{2} \mathrm{~g}_{\mathrm{m} 3}+\mathrm{sC}_{1} \mathrm{~g}_{\mathrm{m} 1} \mathrm{~g}_{\mathrm{m} 4}+\mathrm{g}_{\mathrm{m} 1} \mathrm{~g}_{\mathrm{m} 2} \mathrm{~g}_{\mathrm{m} 3}} \\
& \frac{V_{\mathrm{o} 3}}{V_{\text {in }}}=\frac{\mathrm{s}^{2} \mathrm{C}_{1} \mathrm{C}_{2} \mathrm{~g}_{\mathrm{m} 3}+\mathrm{g}_{\mathrm{m} 1} \mathrm{~g}_{\mathrm{m} 2} \mathrm{~g}_{\mathrm{m} 3}}{\mathrm{~s}^{2} \mathrm{C}_{1} \mathrm{C}_{2} \mathrm{~g}_{\mathrm{m} 3}+\mathrm{sC}_{1} \mathrm{~g}_{\mathrm{m} 1} \mathrm{~g}_{\mathrm{m} 4}+\mathrm{g}_{\mathrm{m} 1} \mathrm{~g}_{\mathrm{m} 2} \mathrm{~g}_{\mathrm{m} 3}}
\end{aligned}
$$

As indicated in Equations (4)-(6), a non-inverting LP filtering function is obtained from $V_{\mathrm{o} 1}$, an inverting BP (IBP) filtering function is obtained from $V_{\mathrm{O} 2}$, and a non-inverting $\mathrm{BR}$ filtering function is obtained from $\mathrm{V}_{\mathrm{o} 3}$.

With the inspection of Equations (1)-(3), the filter parameters $\omega_{\mathrm{o}}$ and $\mathrm{Q}$ are obtained as

$$
\omega_{\mathrm{o}}=\sqrt{\frac{g_{\mathrm{m} 1} g_{\mathrm{m} 2}}{C_{1} C_{2}}}, Q=\frac{g_{\mathrm{m} 3}}{g_{\mathrm{m} 4}} \sqrt{\frac{C_{2} g_{\mathrm{m} 2}}{C_{1} g_{\mathrm{m} 1}}}
$$

From Equation (7), the filter parameter $\omega_{\mathrm{o}}$ can be tuned through the $\mathrm{g}_{\mathrm{m} 1}$ and $\mathrm{g}_{\mathrm{m} 2}$ first and the filter parameter $Q$ can be adjusted independently through $g_{\mathrm{m} 3}$ and/or $g_{\mathrm{m} 4}$ without disturbing $\omega_{\mathrm{o}}$. Moreover, by selecting $\mathrm{g}_{\mathrm{m} 1}=\mathrm{g}_{\mathrm{m} 2}=\mathrm{g}_{\mathrm{m}}$ and $\mathrm{C}_{1}=\mathrm{C}_{2}=\mathrm{C}$, the parameters of $\omega_{\mathrm{o}}$ and $\mathrm{Q}$ in Equation (7) are expressed as

$$
\omega_{\mathrm{o}}=\frac{\mathrm{g}_{\mathrm{m}}}{\mathrm{C}}, \mathrm{Q}=\frac{\mathrm{g}_{\mathrm{m} 3}}{\mathrm{~g}_{\mathrm{m} 4}}
$$

Equation (8) shows that the filter parameters of $\omega_{\mathrm{o}}$ and $Q$ can be non-interactively electronically tuned by varying $g_{\mathrm{m}}, g_{\mathrm{m} 3}$ and/or $\mathrm{g}_{\mathrm{m} 4}$. This means that the parameters $\omega_{\mathrm{o}}$ and $\mathrm{Q}$ of the $\mathrm{VM}$ biquad filter can be independently controlled.

Case II: According to Equation (3), with $\mathrm{g}_{\mathrm{m} 1}=\mathrm{g}_{\mathrm{m} 3}$ and $\mathrm{g}_{\mathrm{m} 2}=\mathrm{g}_{\mathrm{m} 4}=\mathrm{kg}_{\mathrm{m} 1}$, the voltage transfer function is as

$$
V_{\mathrm{o} 3}=\frac{-\mathrm{s}^{2} \mathrm{~V}_{\mathrm{i} 1}-\mathrm{s} \frac{\mathrm{k}}{\tau_{2}}\left(\mathrm{~V}_{\mathrm{i} 2}-\mathrm{V}_{\mathrm{i} 4}\right)+\left(\mathrm{s}^{2}+\frac{1}{\tau_{1} \tau_{2}}\right) \mathrm{V}_{\mathrm{i} 3}}{\mathrm{~s}^{2}+\mathrm{s} \frac{\mathrm{k}}{\tau_{2}}+\frac{1}{\tau_{1} \tau_{2}}}
$$

where $\mathrm{k}$ is a scaling factor, $\tau_{1}=\frac{\mathrm{C}_{1}}{\mathrm{~g}_{\mathrm{m} 2}}$ and $\tau_{2}=\frac{\mathrm{C}_{2}}{\mathrm{~g}_{\mathrm{m} 1}}$ are the realized time-constants.

The specializations of the numerator in Equation (9) results in the VM universal biquad standard filtering functions:

(1) LP filter: $\mathrm{V}_{\mathrm{i} 1}=\mathrm{V}_{\mathrm{i} 3}=\mathrm{V}_{\mathrm{in}}$, and $\mathrm{V}_{\mathrm{i} 2}=\mathrm{V}_{\mathrm{i} 4}=0$.

(2) IBP filter: $\mathrm{V}_{\mathrm{i} 2}=\mathrm{V}_{\mathrm{in}}$, and $\mathrm{V}_{\mathrm{i} 1}=\mathrm{V}_{\mathrm{i} 3}=\mathrm{V}_{\mathrm{i} 4}=0$.

(3) BP filter: $V_{\mathrm{i} 4}=V_{\mathrm{in}}$, and $\mathrm{V}_{\mathrm{i} 1}=\mathrm{V}_{\mathrm{i} 2}=\mathrm{V}_{\mathrm{i} 3}=0$.

(4) IHP filter: $V_{\mathrm{i} 1}=V_{\mathrm{in}}$, and $\mathrm{V}_{\mathrm{i} 2}=\mathrm{V}_{\mathrm{i} 3}=\mathrm{V}_{\mathrm{i} 4}=0$.

(5) BR filter: $\mathrm{V}_{\mathrm{i} 3}=\mathrm{V}_{\mathrm{in}}$, and $\mathrm{V}_{\mathrm{i} 1}=\mathrm{V}_{\mathrm{i} 2}=\mathrm{V}_{\mathrm{i} 4}=0$.

(6) AP filter: $\mathrm{V}_{\mathrm{i} 2}=\mathrm{V}_{\mathrm{i} 3}=\mathrm{V}_{\mathrm{in}}$, and $\mathrm{V}_{\mathrm{i} 1}=\mathrm{V}_{\mathrm{i} 4}=0$.

Obviously, the proposed versatile VM biquad can be used as a multifunction filter with single input and three outputs, as well as a universal filter with four inputs and a single output. Therefore, the proposed VM biquad has more versatility than a single-input-three-output multifunction VM biquad or a multiple-input-single-output universal VM biquad. 


\subsection{Modification of Proposed Filter as VM Quadrature Oscillator}

By connecting node $\mathrm{V}_{\mathrm{o} 2}$ to $\mathrm{V}_{\mathrm{i} 4}$ and leaving the other voltage inputs as zero in the circuit in Figure 3, the VM quadrature oscillator can be obtained as illustrated in Figure 4. The characteristic equation of the VM quadrature oscillator is obtained in Figure 4:

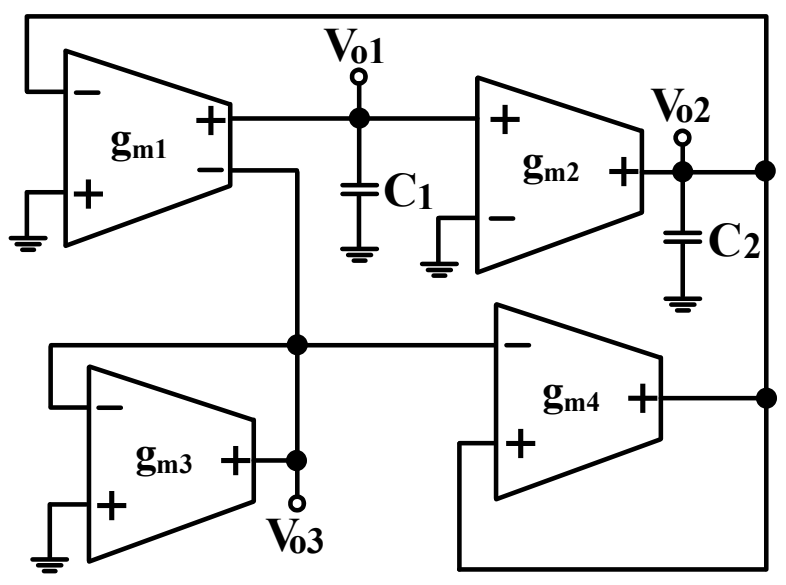

Figure 4. The proposed VM quadrature oscillator.

$$
\mathrm{s}^{2} \mathrm{C}_{1} \mathrm{C}_{2} \mathrm{~g}_{\mathrm{m} 3}+\mathrm{sC}_{1}\left(\mathrm{~g}_{\mathrm{m} 1}-\mathrm{g}_{\mathrm{m} 3}\right) \mathrm{g}_{\mathrm{m} 4}+\mathrm{g}_{\mathrm{m} 1} \mathrm{~g}_{\mathrm{m} 2} \mathrm{~g}_{\mathrm{m} 3}=0
$$

Based on Equation (10), the $\mathrm{CO}$ and the FO are:

$$
\begin{gathered}
\mathrm{CO}: \mathrm{f}_{\mathrm{o}}=\frac{1}{2 \pi} \sqrt{\frac{\mathrm{g}_{\mathrm{m} 1 \mathrm{~g}_{2}}}{\mathrm{C}_{1} \mathrm{C}_{2}}} \\
\mathrm{FO}: \mathrm{g}_{\mathrm{m} 1} \leq \mathrm{g}_{\mathrm{m} 3}
\end{gathered}
$$

From Equations (11) and (12), the CO can be set by $\mathrm{g}_{\mathrm{m} 2}$ without affecting the FO. The FO can also be set by $\mathrm{g}_{\mathrm{m} 3}$ without affecting the $\mathrm{CO}$. Thus, the proposed $\mathrm{VM}$ quadrature oscillator supplies the independent control of $\mathrm{CO}$ and FO. The relationship between the voltage outputs $\mathrm{V}_{\mathrm{o} 1}$ and $\mathrm{V}_{\mathrm{o} 2}$ of Figure 4 is represented by the following expression:

$$
\frac{\mathrm{V}_{\mathrm{o} 1}}{\mathrm{~V}_{\mathrm{o} 2}}=-\frac{\mathrm{g}_{\mathrm{m} 1}}{\mathrm{sC}_{1}}
$$

From Equation (13), the output voltages $\mathrm{V}_{\mathrm{o} 1}$ and $\mathrm{V}_{\mathrm{o} 2}$ have a phase difference of $90^{\circ}$ and are called quadrature signals. The phase of output $V_{\mathrm{o} 1}$ leads the phase of output voltage $\mathrm{V}_{\mathrm{o} 2}$ by $90^{\circ}$.

\section{Effect of the Parasitic Impedances in OTA}

An ideal DO-OTA is a voltage-controlled current source, with unlimited bandwidth, and unlimited input and output impedance. The non-ideal dual-output currents of DO-OTA are characterized as $\mathrm{I}_{\mathrm{O}+}$ $=\alpha \mathrm{g}_{\mathrm{m}}\left(\mathrm{V}_{+}-\mathrm{V}_{-}\right)$and $\mathrm{I}_{\mathrm{O}_{-}}=-\beta \mathrm{g}_{\mathrm{m}}\left(\mathrm{V}_{+}-\mathrm{V}_{-}\right)$, where $\alpha=1-\varepsilon_{\alpha \mathrm{i}}$ and $\beta=1-\varepsilon_{\beta \mathrm{i}}$. Here, $\varepsilon_{\alpha \mathrm{i}}\left(\left|\varepsilon_{\alpha \mathrm{i}}\right|\right.$ «1) and $\varepsilon_{\beta \mathrm{i}}\left(\left|\varepsilon_{\beta \mathrm{i}}\right| \ll 1\right)$ represent non-ideal DO-OTA current tracking errors. Practically, the performances of the proposed circuits are affected by the internal current tracking errors and the parasitic terminal impedances of the DO-OTA. Figure 5 shows the non-ideal DO-OTA model. The effect of current tracking error and parasitic impedance on the parameters of $\omega_{\mathrm{o}}$ and $\mathrm{Q}$ has been investigated to indicate the performance of the filter. For example, if the parasitic effect is considered, and the parasitic capacitance and parasitic resistance are added to Figure 3, the new topology is shown in Figure 6. The influences of the parasitic impedances of $\mathrm{V}_{+1}, \mathrm{~V}_{-2}, \mathrm{~V}_{+3}$ and $\mathrm{V}_{+4}$ terminals will be negligible 
because they are connected to input voltage source. Taking into account the current tracking errors and parasitic elements shown in Figure 6 and reanalyzing the versatile VM biquadratic filter, the following characteristic equation $\mathrm{D}(\mathrm{s})$ is obtained:

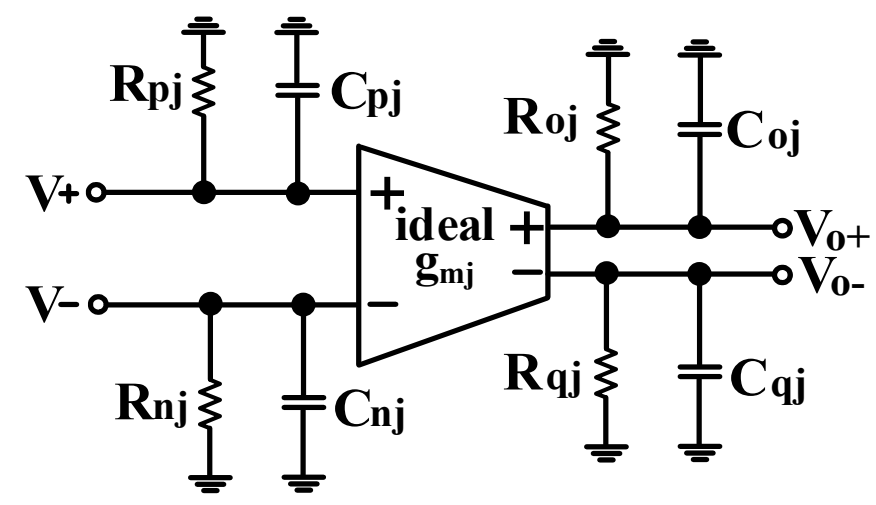

Figure 5. The non-ideal DO-OTA model.

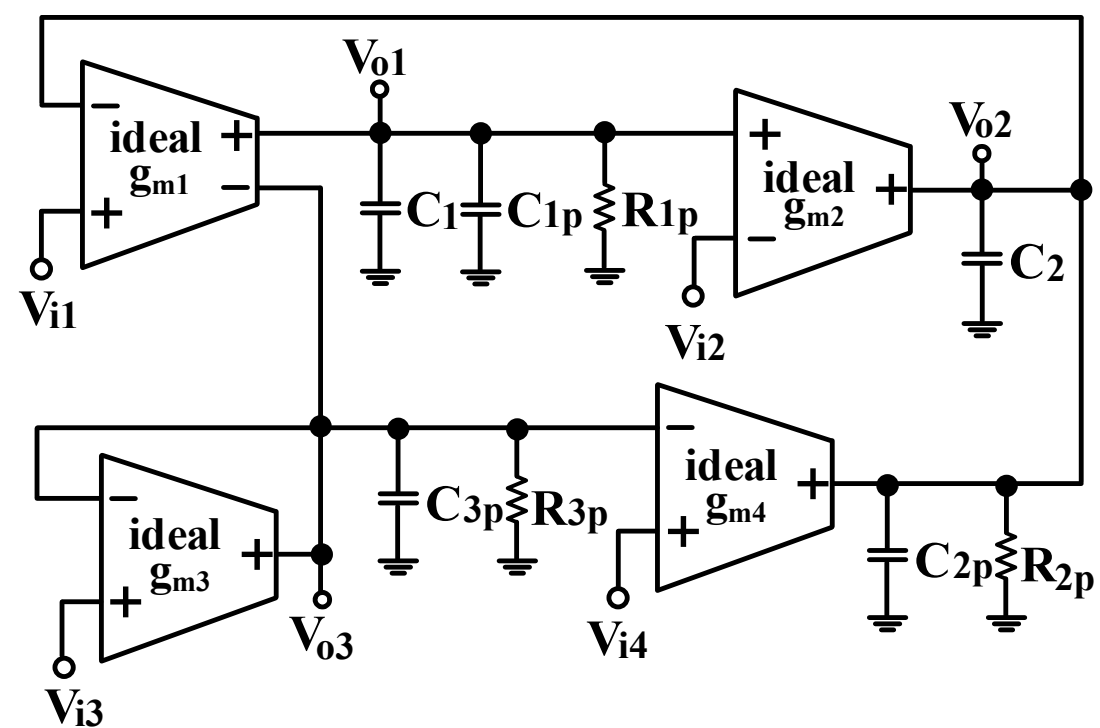

Figure 6. Proposed versatile VM biquad filter including the parasitic components of OTAs.

$$
\begin{aligned}
& \mathrm{D}(\mathrm{s})=\alpha_{3} \mathrm{~s}^{2} \mathrm{C}_{1} \mathrm{C}_{2} \mathrm{~g}_{\mathrm{m} 3}\left(1+\frac{\mathrm{C}_{1} \mathrm{C}_{2} \mathrm{G}_{3 \mathrm{p}}+\mathrm{C}_{1} \mathrm{G}_{2 \mathrm{p}} \mathrm{C}_{3 \mathrm{p}}+\mathrm{C}_{2} \mathrm{G}_{1 \mathrm{p}} \mathrm{C}_{3 \mathrm{p}}}{\alpha_{3} \mathrm{C}_{1} \mathrm{C}_{2} \mathrm{~g}_{\mathrm{m} 3}}\right) \\
& +\beta_{1} \alpha_{4} \mathrm{sC}_{1} \mathrm{~g}_{\mathrm{m} 1} \mathrm{~g}_{\mathrm{m} 4}\left(1+\frac{\mathrm{C}_{1} \mathrm{G}_{2 \mathrm{p}} \mathrm{G}_{3 \mathrm{p}}+\mathrm{C}_{1} \mathrm{G}_{2 \mathrm{p}} \alpha_{3} \mathrm{~g}_{\mathrm{m} 3}+\mathrm{C}_{2} \mathrm{G}_{1 \mathrm{p}} \mathrm{G}_{3 \mathrm{p}}+\mathrm{C}_{2} \mathrm{G}_{1 \mathrm{p}} \alpha_{3} \mathrm{~g}_{\mathrm{m} 3}+\mathrm{C}_{3 \mathrm{p}} \mathrm{G}_{1 \mathrm{p}} \mathrm{G}_{2 \mathrm{p}}+\mathrm{C}_{3 \mathrm{p}} \alpha_{1} \alpha_{2} \mathrm{~g}_{\mathrm{m} 1} \mathrm{~g}_{\mathrm{m} 2}+\mathrm{s}^{2} \mathrm{C}_{1} \mathrm{C}_{2} \mathrm{C}_{3 \mathrm{p}}}{\beta_{1} \alpha_{4} \mathrm{C}_{1} \mathrm{~g}_{\mathrm{m} 1} \mathrm{~g}_{\mathrm{m} 4} \mathrm{~g}_{\mathrm{m}} \mathrm{G}_{1 \mathrm{p}}+\alpha_{1} \alpha_{2} \mathrm{~g}_{\mathrm{m} 1} \mathrm{~g}_{\mathrm{m} 2} \mathrm{G}_{3 \mathrm{p}}}\right) \\
& +\alpha_{1} \alpha_{2} \alpha_{3} g_{m 1} g_{m 2} g_{m 3}\left(1+\frac{G_{1 p} G_{2 p} G_{3 p}+G_{1 p} G_{2 p} \alpha_{3} g_{m 3}+\beta_{1} \alpha_{4} g_{m} g_{m 4} G_{1 p}+\alpha_{1} \alpha_{2} g_{m 1} g_{m 2} G_{3 p}}{\alpha_{1} \alpha_{2} \alpha_{3} g_{m 1} g_{m 2} g_{m 3}}\right)
\end{aligned}
$$

where $\mathrm{C}_{1}=\mathrm{C}_{1}+\mathrm{C}_{1 \mathrm{p}}, \mathrm{C}_{2}=\mathrm{C}_{2}+\mathrm{C}_{2 \mathrm{p}}, \mathrm{C}_{1 \mathrm{p}}=\mathrm{C}_{\mathrm{o} 1}+\mathrm{C}_{\mathrm{p} 2}, \mathrm{C}_{2 \mathrm{p}}=\mathrm{C}_{\mathrm{o} 2}+\mathrm{C}_{\mathrm{o} 4}+\mathrm{C}_{\mathrm{n} 1}, \mathrm{C}_{3 \mathrm{p}}=\mathrm{C}_{\mathrm{q} 1}+$ $\mathrm{C}_{\mathrm{o} 3}+\mathrm{C}_{\mathrm{n} 3}+\mathrm{C}_{\mathrm{n} 4}, \mathrm{G}_{1 \mathrm{p}}=\frac{1}{\mathrm{R}_{1 \mathrm{p}}}, \mathrm{G}_{2 \mathrm{p}}=\frac{1}{\mathrm{R}_{2 \mathrm{p}}}, \mathrm{G}_{3 \mathrm{p}}=\frac{1}{\mathrm{R}_{3 \mathrm{p}}}, \mathrm{R}_{1 \mathrm{p}}=\mathrm{R}_{\mathrm{o} 1} / / \mathrm{R}_{\mathrm{p} 2}, \mathrm{R}_{2 \mathrm{p}}=\mathrm{R}_{\mathrm{o} 2} / / \mathrm{R}_{\mathrm{o} 4} / / \mathrm{R}_{\mathrm{n} 1}$ and $\mathrm{R}_{3 \mathrm{p}}=\mathrm{R}_{\mathrm{q} 1} / / \mathrm{R}_{\mathrm{o} 3} / / \mathrm{R}_{\mathrm{n} 3} / / \mathrm{R}_{\mathrm{n} 4}$.

The following conditions should be satisfied for a biquad filter:

$$
\begin{gathered}
\frac{1}{\mathrm{sC}_{1}}<<\mathrm{R}_{1 \mathrm{p}} \\
\frac{1}{\mathrm{sC}_{2}}<<\mathrm{R}_{2 \mathrm{p}}
\end{gathered}
$$




$$
\mathrm{sC}_{3 \mathrm{p}}+\mathrm{G}_{3 \mathrm{p}}<<\mathrm{g}_{\mathrm{m} 3}
$$

Under these conditions in Equations (15)-(17), the modified characteristic equation $\mathrm{D}_{1}(\mathrm{~s})$ is determined as

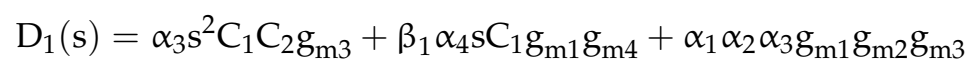

From (18), the modified biquadratic filter parameters of $\omega_{\mathrm{o}}$ and $\mathrm{Q}$ are obtained by

$$
\omega_{\mathrm{o}}=\sqrt{\frac{\alpha_{1} \alpha_{2} g_{\mathrm{m} 1} g_{\mathrm{m} 2}}{C_{1} C_{2}}}, Q=\frac{\alpha_{3} g_{\mathrm{m} 3}}{\beta_{1} \alpha_{4} g_{\mathrm{m} 4}} \sqrt{\frac{\alpha_{1} \alpha_{2} C_{2} g_{\mathrm{m} 2}}{C_{1} g_{\mathrm{m} 1}}}
$$

The active and passive sensitivities of the biquadratic filter parameters $\omega_{\mathrm{o}}$ and $\mathrm{Q}$ in Equation (19) remain less than or equal to one in magnitude. Hence, the proposed filter has a good sensitivity performance.

\section{Simulation and Experimental Results}

Simulation and measurement are essential to verify the theoretical analysis. The theoretical analysis of the proposed filter in Figure 3 and the oscillator in Figure 4 is verified by using PSpice for simulation and commercial LT1228 OTA for implementation. The experimental power supply voltages were $\pm 15 \mathrm{~V}$. According to the LT1228 datasheet [50], the transconductance gain is given by $\mathrm{g}_{\mathrm{m}}=10 \mathrm{I}_{\mathrm{SET}}$, where $\mathrm{I}_{\mathrm{SET}}$ is the bias current of LT1228. This feature makes it useful for the electronic control of transconductance gain.

\subsection{Versatile VM Biquad Filter Simulation and Experimental Results}

The proposed filter is verified by simulation and experimental results. The filter was designed to obtain the natural frequency of $f_{O}=144.7 \mathrm{kHz}$ and $Q=1$. In this case, the passive component values of Figure 3 were chosen as $C_{1}=C_{2}=2.2 \mathrm{nF}$ and $g_{\mathrm{m} 1}=g_{\mathrm{m} 2}=g_{\mathrm{m} 3}=g_{\mathrm{m} 4}=2 \mathrm{mS}$ (i.e., $\mathrm{I}_{\mathrm{b}}=200 \mathrm{uA}$ ). Figures 7-9 show the gain and phase of simulation and measurement responses of $L P\left(V_{o 1}\right)$, IBP $\left(V_{o 2}\right)$, and $\mathrm{BR}\left(\mathrm{V}_{\mathrm{O} 3}\right)$ filters, respectively, as depicted in Equations (4)-(6). Figures 10-14 show the gain and phase responses of the simulation and measurement of LP, BP, IBP, IHP, and AP filters, respectively. The simulation and measurement results are in accordance with the theoretical value of Equation (9). The power consumption of simulation and measurement are approximately $0.92 \mathrm{~W}$ and $1.23 \mathrm{~W}$, respectively. To verify the tunable electronic property of parameter $f_{0}$ without affecting the parameter $\mathrm{Q}$, the tuning transconductance gains, $\mathrm{g}_{\mathrm{m} 1}=\mathrm{g}_{\mathrm{m} 2}$, were simultaneously changed to $1.5 \mathrm{mS}, 2 \mathrm{mS}$ and $3 \mathrm{mS}$, while keeping $\mathrm{C}_{1}=\mathrm{C}_{2}=2.2 \mathrm{nF}$, and $\mathrm{g}_{\mathrm{m} 3}=\mathrm{g}_{\mathrm{m} 4}=2 \mathrm{mS}$ for constant $\mathrm{Q}=1$. Figure 15 shows the simulated and measured gain responses of the $\mathrm{BP}$ responses on the $\mathrm{V}_{\mathrm{o} 3}$ output terminal when $V_{i 4}=V_{\text {in }}$ and $V_{i 1}=V_{i 2}=V_{i 3}=0$. This illustrates the tunable property of parameter $f_{o}$ without affecting parameter $\mathrm{Q}$. However, to verify the tunable electronic property of parameter $\mathrm{Q}$ without affecting parameter $\mathrm{f}_{\mathrm{o}}$, the transconductance gain $\mathrm{g}_{\mathrm{m} 4}$ was given as $2 \mathrm{mS}, 1.5 \mathrm{mS}$ and $1 \mathrm{mS}$, while keeping $C_{1}=C_{2}=2.2 \mathrm{nF}$ and $g_{\mathrm{m} 1}=g_{\mathrm{m} 2}=g_{\mathrm{m} 3}=2 \mathrm{mS}$ for constant $\mathrm{f}_{\mathrm{o}}=144.7 \mathrm{kHz}$. Figure 16 shows the simulated and measured frequency gain responses of the BP responses on the $V_{03}$ output terminal when $V_{i 4}=V_{\text {in }}$ and $V_{i 1}=V_{i 2}=V_{i 3}=0$. This illustrates the tunable property of parameter $Q$ without affecting the parameter $f_{o}$. These results show that by using various values of $g_{m 4}$, the parameter $Q$ can be easily adjusted without affecting the parameter $f_{o}$, as explained in Equation (7). 


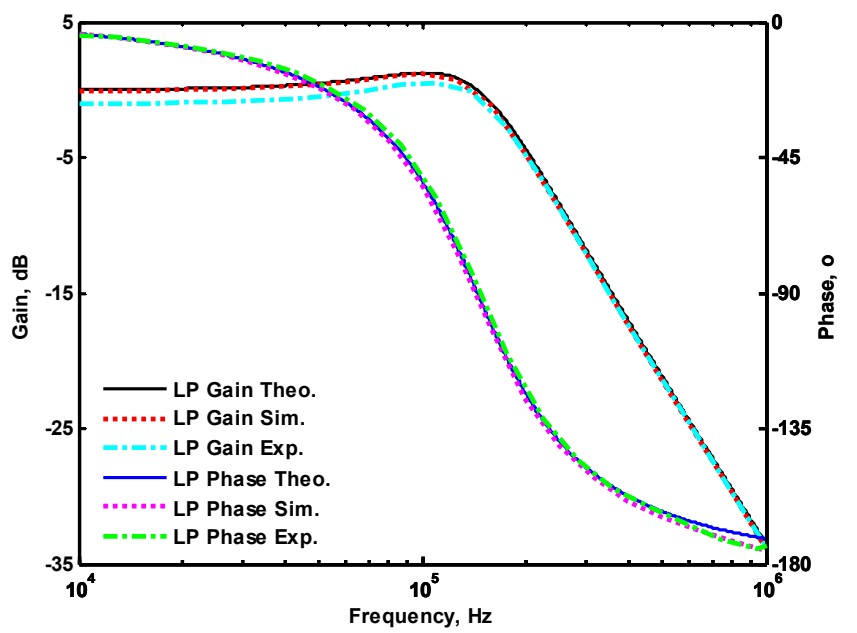

Figure 7. Experimental and simulated low-pass (LP) filters with theoretical responses.

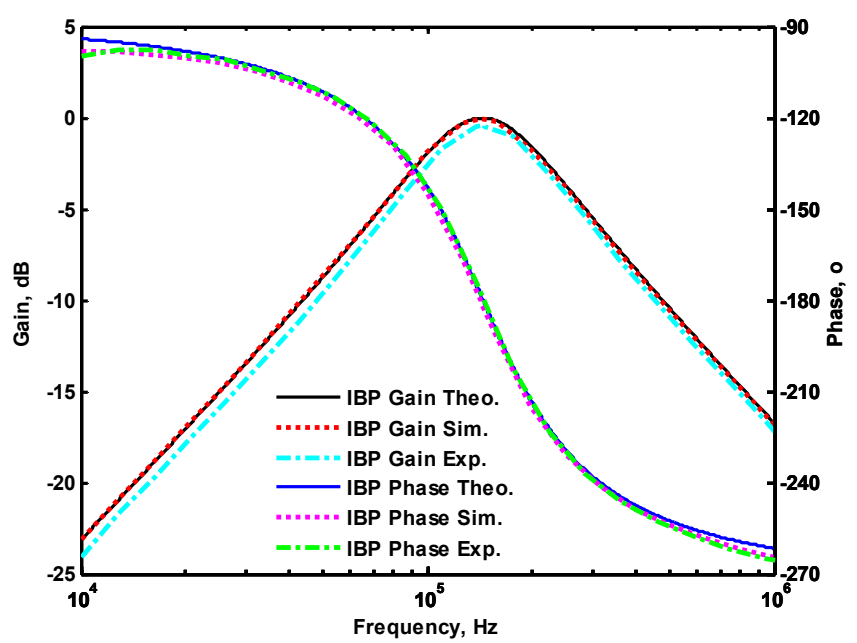

Figure 8. Experimental and simulated inverted band-pass (IBP) filters with theoretical responses.

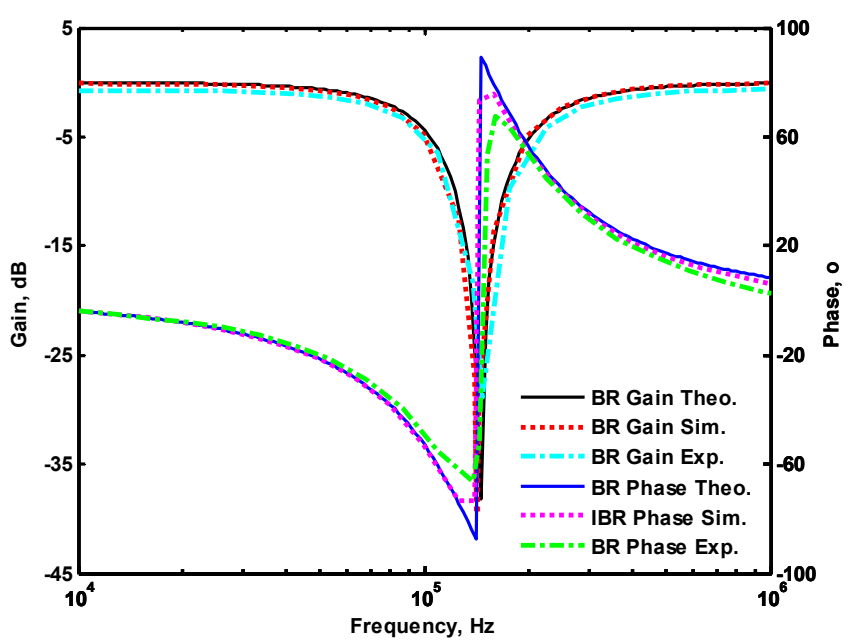

Figure 9. Experimental and simulated band-reject (BR) filters with theoretical responses. 


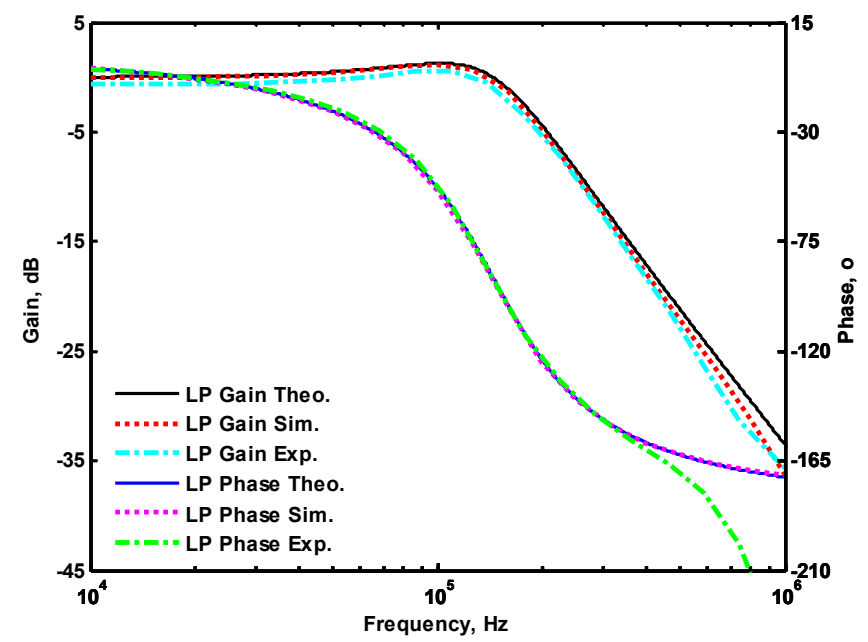

Figure 10. Experimental and simulated LP filters with theoretical responses in case II.

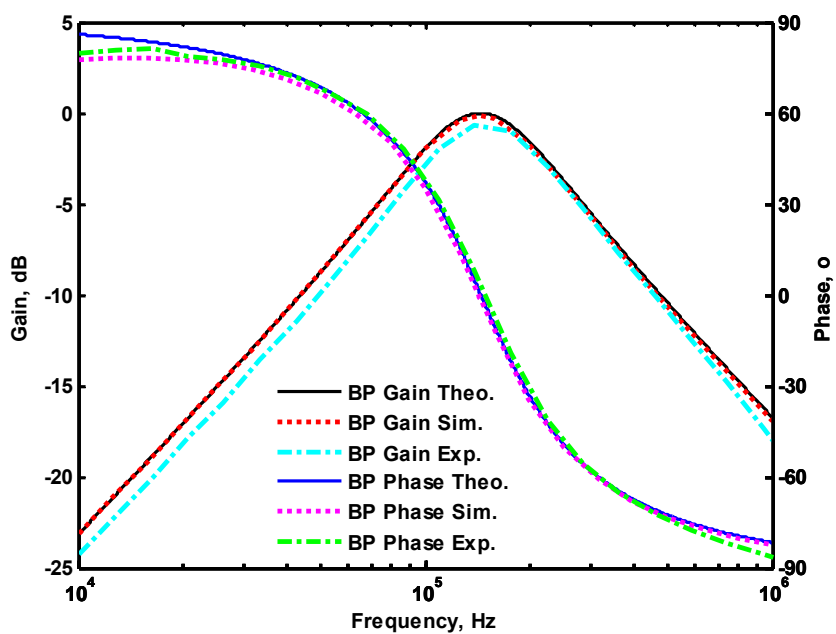

Figure 11. Experimental and simulated BP filters with theoretical responses in case II.

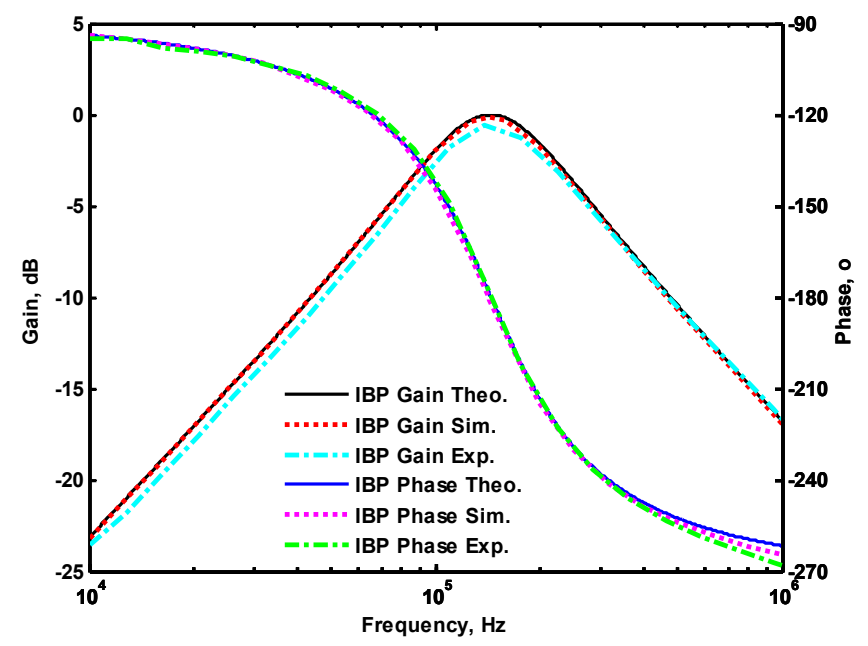

Figure 12. Experimental and simulated IBP filters with theoretical responses in case II. 


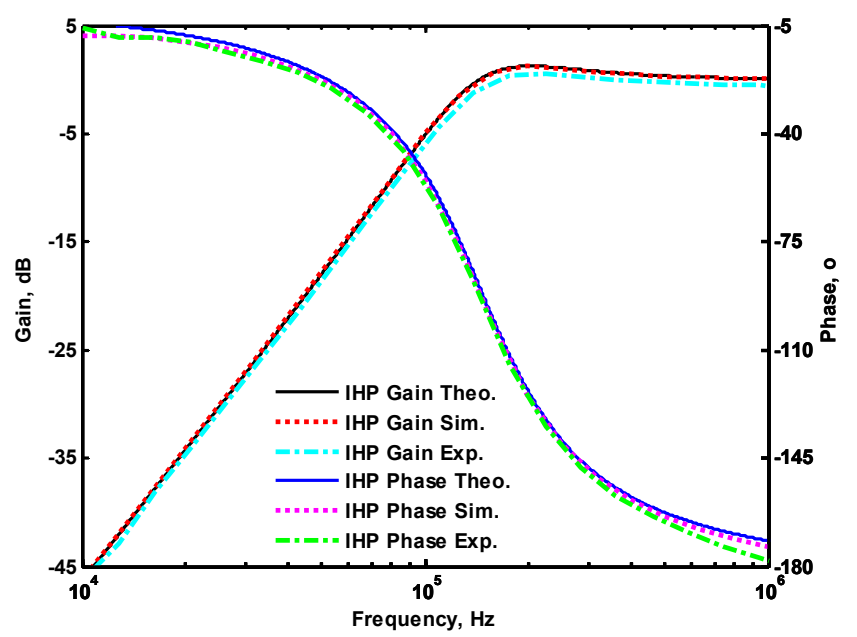

Figure 13. Experimental and simulated inverted high-pass (IHP) filters with theoretical responses in case II.

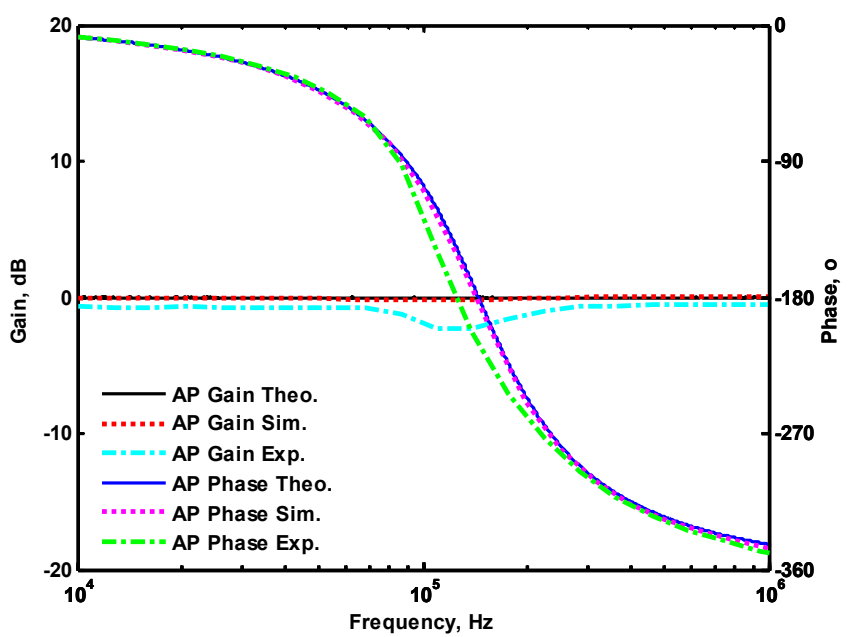

Figure 14. Experimental and simulated all-pass (AP) filters with theoretical responses in case II.

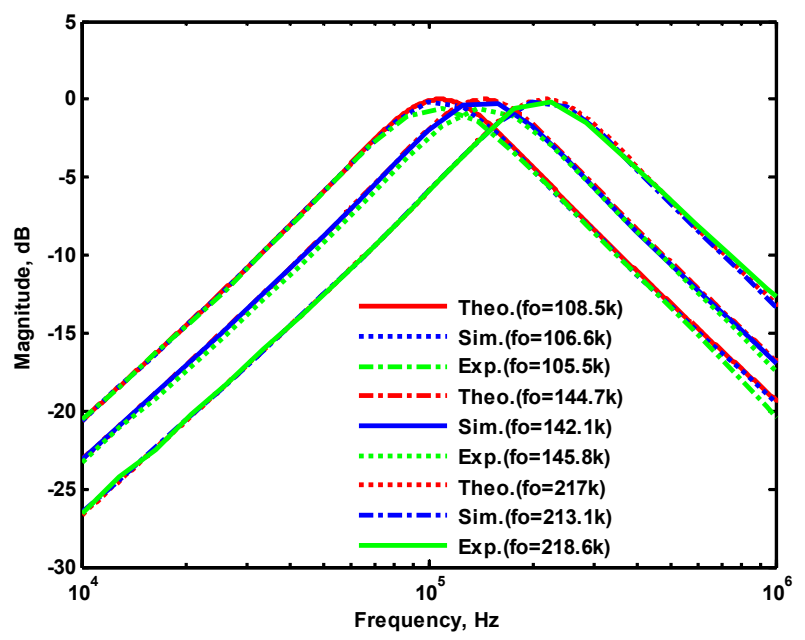

Figure 15. Theoretical, simulated, and measured gain responses of BP filters realized by varying $\mathrm{f}_{\mathrm{o}}$ while keeping $Q$. 


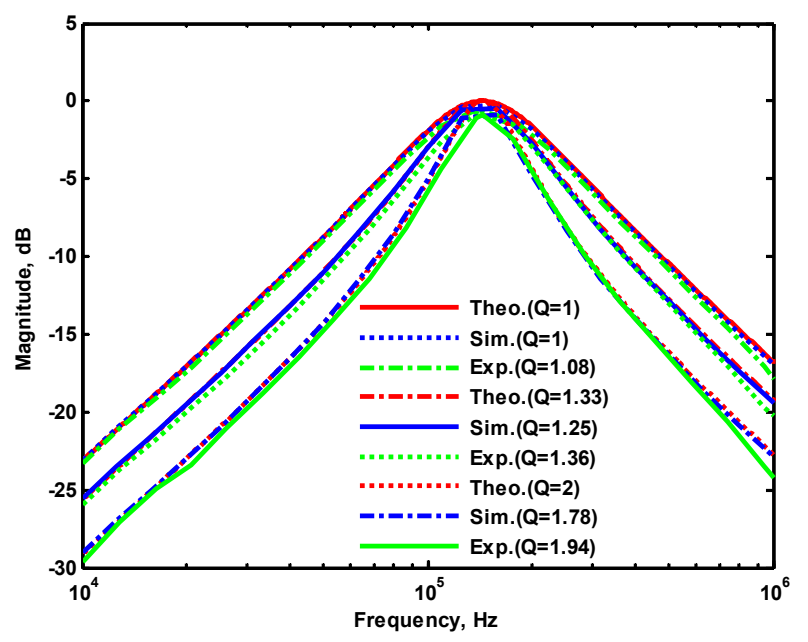

Figure 16. Theoretical, simulated, and measured gain responses of BP filters realized by varying $Q$ while keeping $\mathrm{f}_{\mathrm{o}}$.

To verify the input dynamic range of the proposed filter, the simulation was repeated for a sinusoidal input signal with $\mathrm{f}_{\mathrm{O}}=144.69 \mathrm{kHz}$. Figure 17 shows the input signal and output signal transient waveforms of the BP response on the $V_{\mathrm{o} 3}$ output terminal when $V_{i 4}=V_{i n}$ and $V_{i 1}=V_{i 2}=V_{i 3}=0$. The expansion amplitude is $120 \mathrm{mV}_{\mathrm{pp}}$ (peak to peak) without signification distortion. The dependence of the $\mathrm{V}_{\mathrm{o} 3}$ output harmonic distortion of the $\mathrm{BP}$ responses on input voltage amplitude is illustrated in Figure 18. Figure 18 shows that the total harmonic distortion (THD) is about $3.83 \%$ when the input signal increases to $170 \mathrm{mV}_{\mathrm{pp}}$. For the experimental testing, Figure 19 shows the measured input and output voltage waveforms for the BP response, which can be extended to an amplitude of 120 $m V_{p p}$ without signification distortion. Figure 20 shows the spectrum of the BP response of Figure 19. The measured angular frequency is about $144 \mathrm{kHz}$, which is close to the theoretical value of $144.69 \mathrm{kHz}$ and the error rate is $0.48 \%$. The THD, including the first harmonic to the fifth harmonic components of Figure 20, is about $2.13 \%$. To verify the linear performance of the proposed filter, the $1 \mathrm{~dB}$ compression point of the circuit characteristics must be evaluated. Figure 21 shows the measured P1dB of the BP filter output voltage $V_{\mathrm{o} 3}$ by applying input power at an angular frequency of $144.69 \mathrm{kHz}$, when $V_{\mathrm{i} 4}=V_{\text {in }}$, and $V_{i 1}=V_{i 2}=V_{i 3}=0$. As shown in Figure 21, relative to the output power, the measured P1dB of BP filter is about $-5.9 \mathrm{dBm}$. Furthermore, to represent the nonlinearity of the filter proposed in Figure 3, a two-tone test of intermodulation distortion (IMD) was used to characterize the nonlinearity of the BP response. Figure 22 shows the frequency spectrum of the BP response at the $\mathrm{V}_{03}$ output terminal, where $\mathrm{V}_{\mathrm{i} 4}=\mathrm{V}_{\mathrm{in}}$, and $\mathrm{V}_{\mathrm{i} 1}=\mathrm{V}_{\mathrm{i} 2}=\mathrm{V}_{\mathrm{i} 3}=0$. The BP filter has inter-modulation characteristics by applying two-tone signals around $144.69 \mathrm{kHz}$. In Figure 22, two closely spaced tones, $\mathrm{f}_{1}=143.69 \mathrm{kHz}$ and $\mathrm{f}_{2}=145.69 \mathrm{kHz}$, were used with an equal input amplitude of $63 \mathrm{mVpp}$. The measured value of the third-order IMD is about $-48.67 \mathrm{dBc}$, and the third-order intercept (TOI) point is approximately $-2.597 \mathrm{dBm}$. The component values used in Figures $17-22$ were $\mathrm{C}_{1}=\mathrm{C}_{2}=2.2 \mathrm{nF}$ and $\mathrm{g}_{\mathrm{mi}}=2 \mathrm{mS}(\mathrm{i}=1$ to 4 ), leading to a center frequency of $f_{o}=144.69 \mathrm{kHz}$. 


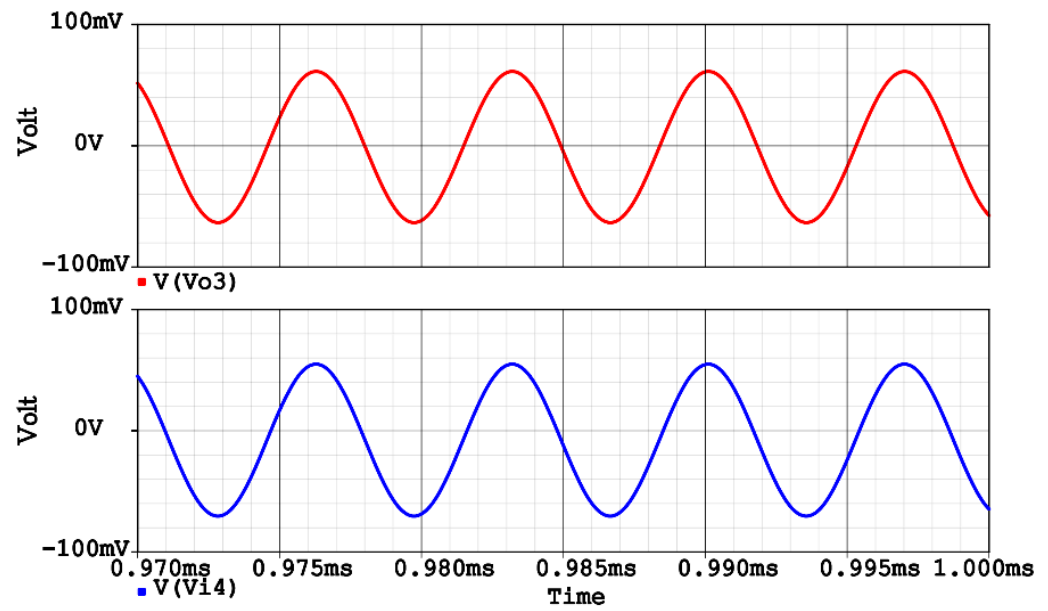

Figure 17. Simulated time-domain voltage input (blue line) and voltage output (red line) signals of BP filter.

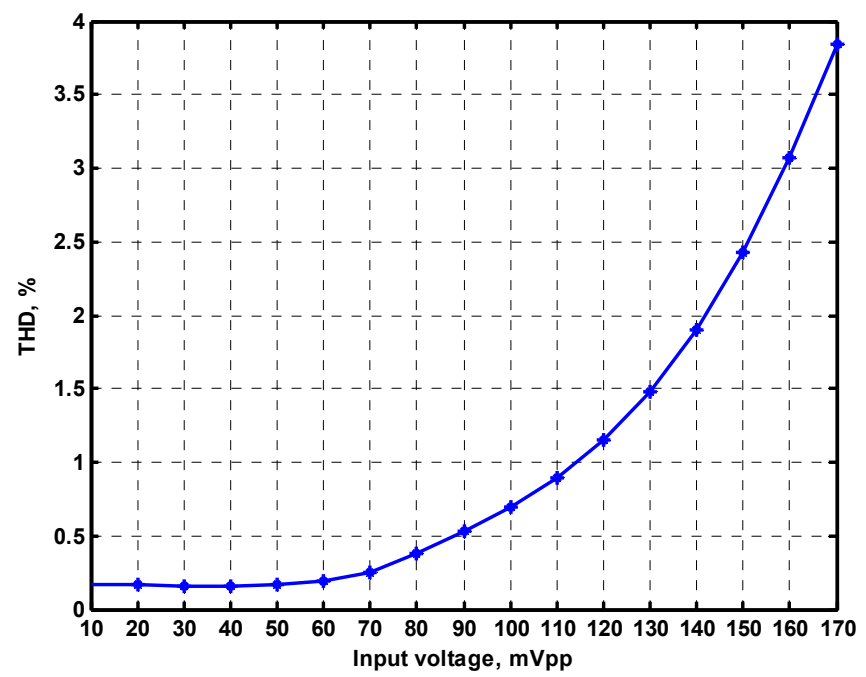

Figure 18. Total harmonic distortion (THD) analysis results of BP response.

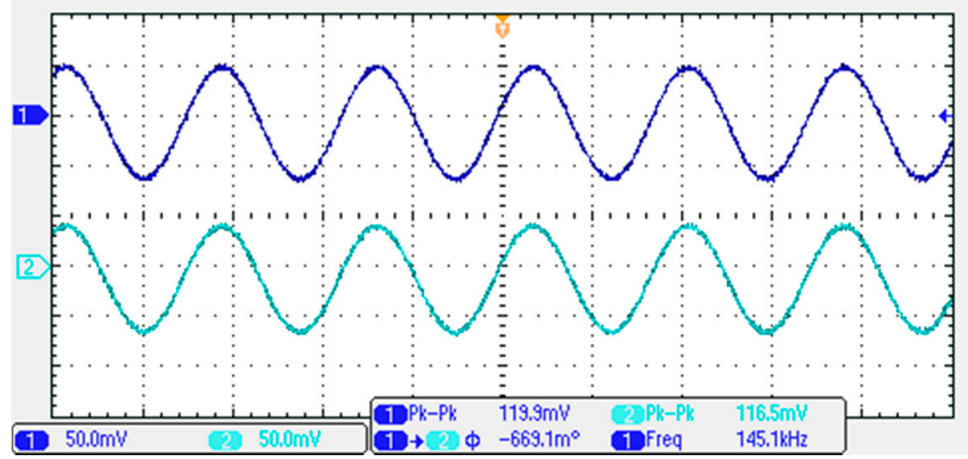

Figure 19. The experimental time-domain voltage input (channel 1, blue line) and voltage output (channel 2, cyan line) signals of the BP filter of $\mathrm{V}_{\mathrm{o} 3}$ output terminal. 


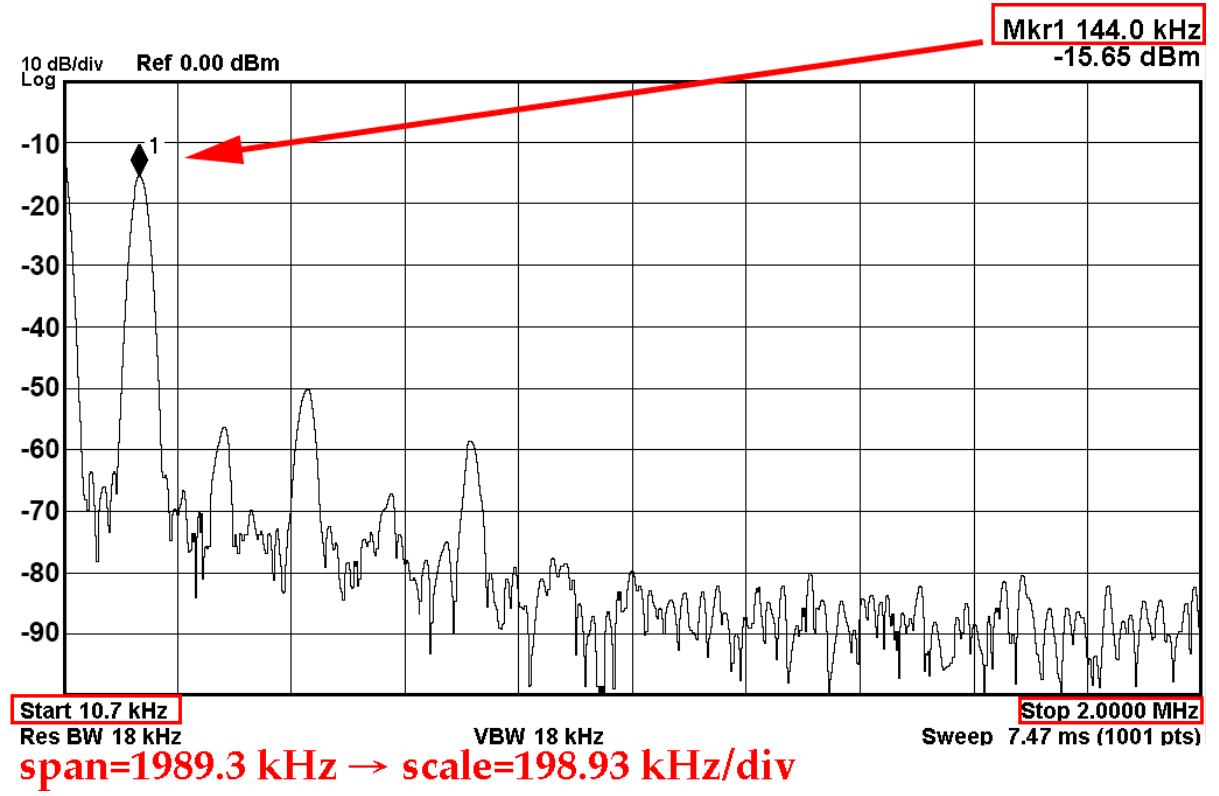

Figure 20. The experimental BP frequency spectrum analysis of Figure 19.

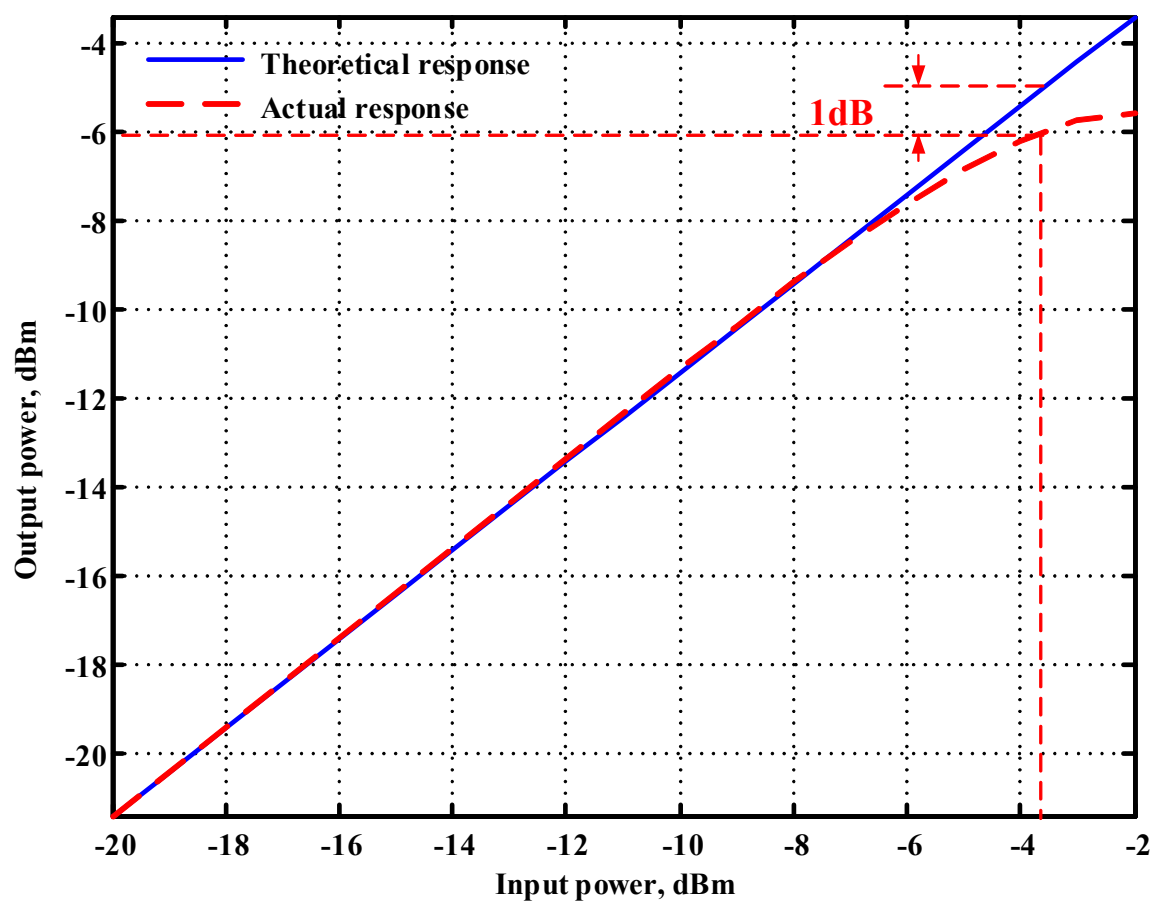

Figure 21. Measured P1dB of the BP filter with the input power of the voltage output $\mathrm{V}_{\mathrm{o} 3}$. 


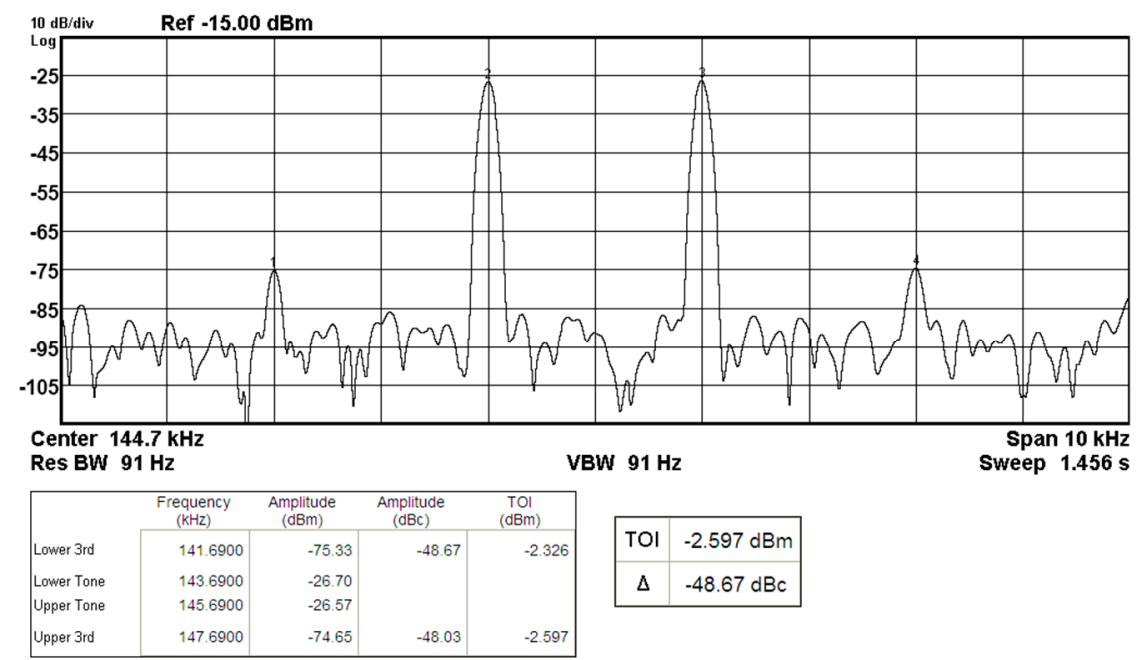

Figure 22. Third-order intercept (TOI) measurement of BP filter.

To collect statistics on the effects of mismatch and change in Figure 3, Monte-Carlo simulations were performed by choosing a 5\% tolerance for the capacitor values in Figure 3 and running 100 times in each case. The results when the two capacitor values are 5\% Gaussian deviation are shown in Figure 23. In Figure 23, the center frequency of the nominal design was $\mathrm{f}_{\mathrm{o}}=144.7 \mathrm{kHz}$ by choosing $\mathrm{C}_{1}=\mathrm{C}_{2}=2.2 \mathrm{nF}$ and $\mathrm{g}_{\mathrm{mi}}=2 \mathrm{mS}(\mathrm{i}=1$ to 4 ), and the Monte-Carlo analysis shows the median value of $141.8 \mathrm{kHz}$. The results show that the center frequency achieved by the mismatch of two capacitor values in the proposed circuit has little effect and is completely within the acceptable range. According the Monte-Carlo simulation, as the center frequency varies between 125 and $162.7 \mathrm{kHz}$, the $\mathrm{f}_{\mathrm{o}}$-value of the $\mathrm{BP}$ response on the $\mathrm{V}_{\mathrm{o} 3}$ output terminal was affected in the range of $-13.8-12.2 \%$.

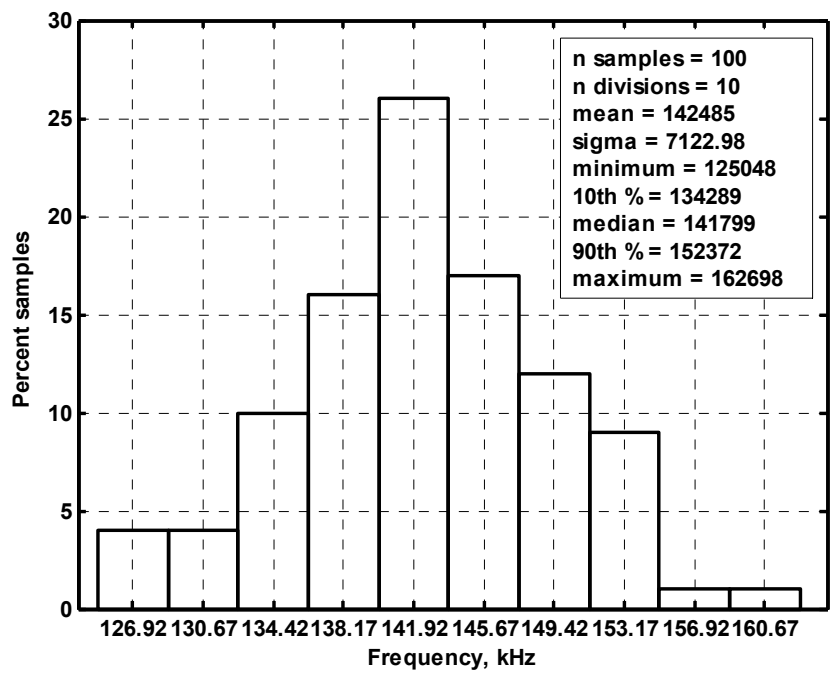

Figure 23. Histogram of the Monte-Carlo analysis for the BP filter.

\subsection{VM Quadrature Oscillator Simulation and Experimental Results}

To confirm the theoretical analysis, the oscillator in Figure 4 is designed as $C_{1}=C_{2}=3 \mathrm{nF}$ and $\mathrm{g}_{\mathrm{m} 1}=\mathrm{g}_{\mathrm{m} 2}=\mathrm{g}_{\mathrm{m} 4}=1 \mathrm{mS}$. In practice, to ensure that the oscillation starts, consider that the value of $\mathrm{g}_{\mathrm{m} 3}=1.013 \mathrm{mS}$ is greater than $\mathrm{g}_{\mathrm{m} 1}$. Figure 24 shows the simulated waveforms of the quadrature voltage outputs $\mathrm{V}_{\mathrm{o} 1}$ and $\mathrm{V}_{\mathrm{o} 2}$ at steady state. The simulated oscillation frequency in Figure 24 is $52.18 \mathrm{kHz}$, which is close to the theoretical value of $53 \mathrm{kHz}$. The error percentage between the theoretical and simulated oscillation frequency is $-1.5 \%$. In the experimental test, the measured oscillation frequency 
is $53.28 \mathrm{kHz}$, which is close to the theoretical value of $53 \mathrm{kHz}$ and the error rate is $0.53 \%$, as shown in Figure 25. The frequency spectrum of the oscillator output voltage, $\mathrm{V}_{\mathrm{o} 2}$, is shown in Figure 26. The measured oscillation frequency is $53.56 \mathrm{kHz}$, which is closed to theoretical value of $53 \mathrm{kHz}$, and the error rate is $1.06 \%$. The THD in Figure 26 is about $2.8 \%$. Figure 27 shows the simulation and experimental results of the oscillation frequency obtained by varying the values of $\mathrm{g}_{\mathrm{m} 2}$ with $\mathrm{C}_{1}=\mathrm{C}_{2}=1 \mathrm{nF}$ (or $3 \mathrm{nF}$ ), $\mathrm{g}_{\mathrm{m} 1}=\mathrm{g}_{\mathrm{m} 4}=1 \mathrm{mS}$ and $\mathrm{g}_{\mathrm{m} 3}=1.013 \mathrm{mS}$. When the tuning transconductance gain, $\mathrm{g}_{\mathrm{m} 2}$ is in the range of $0.5-5 \mathrm{mS}$, to start and maintain the sine wave oscillation under the same oscillation condition, the electronic tuning oscillation frequency range of the oscillator will be between $37.95 \mathrm{kHz}$ and $355.88 \mathrm{kHz}$. The simulation and experimental results are consistent with the theoretical values. For wideband frequency adjustment and amplitude stabilization, the automatic gain control (AGC) system is required. Therefore, an additional auxiliary AGC circuit and technology are necessary. The AGC circuit can improve the unbalance of the voltage amplitude generated and can reduce the THD to achieve better performance. This technique has been presented in the literature [31]. Figures 28 and 29 show how to calculate phase noise using the Agilent's phase noise measurement solution. In Figures 28 and 29, the phase noise of the proposed oscillator is lower than $-75.42 \mathrm{dBc} / \mathrm{Hz}(\mathrm{at} 1 \mathrm{kHz}$ offset) and $-96.71 \mathrm{dBc} / \mathrm{Hz}$ (at $10 \mathrm{kHz}$ offset), respectively.

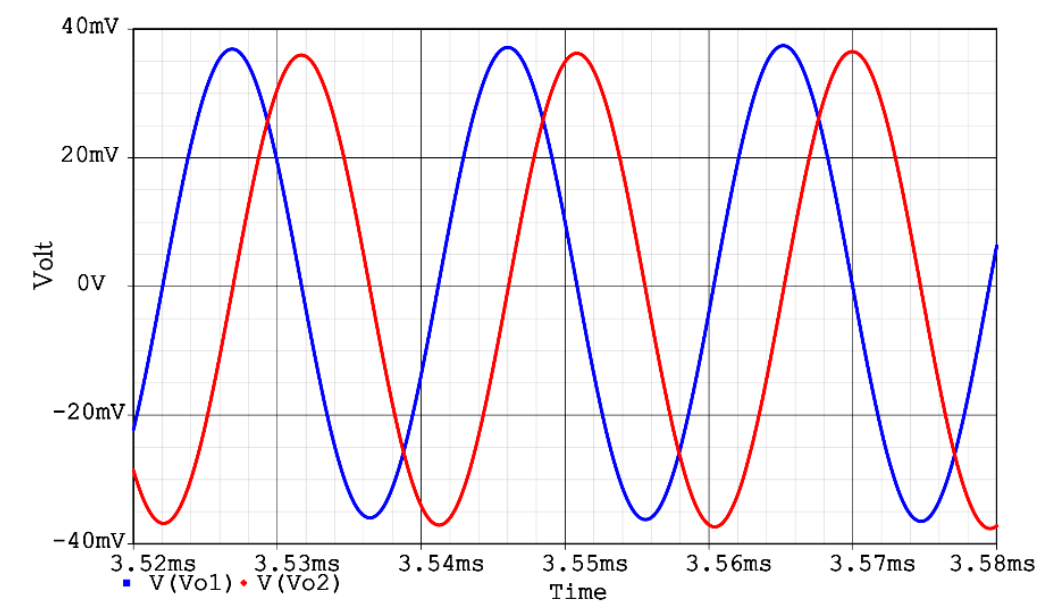

Figure 24. Simulated steady state waveform of the VM quadrature $V_{\mathrm{o} 1}$ (blue) and $\mathrm{V}_{\mathrm{o} 2}$ (red) voltage outputs.

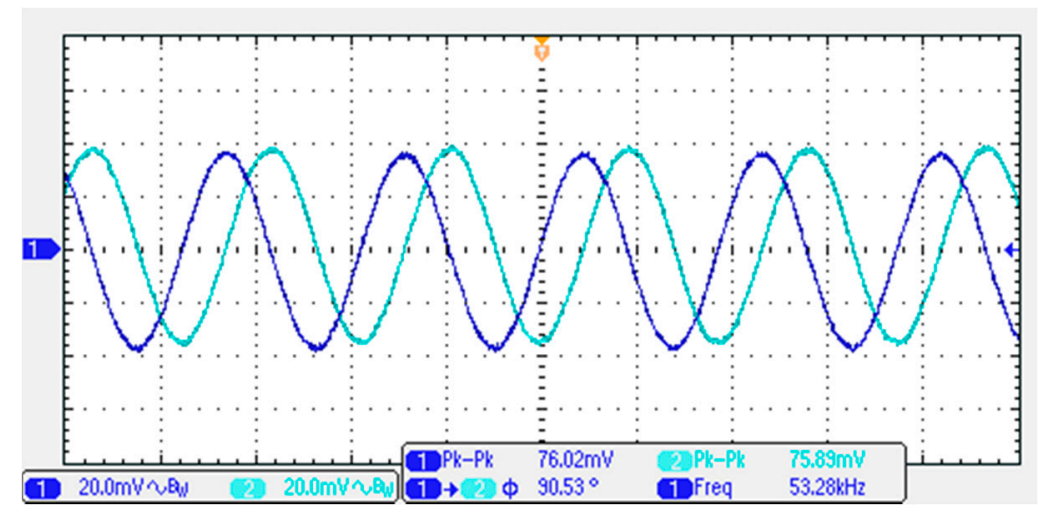

Figure 25. The experimental quadrature $\mathrm{V}_{\mathrm{o} 1}$ (blue) and $\mathrm{V}_{\mathrm{o} 2}$ (cyan) voltage waveforms. 


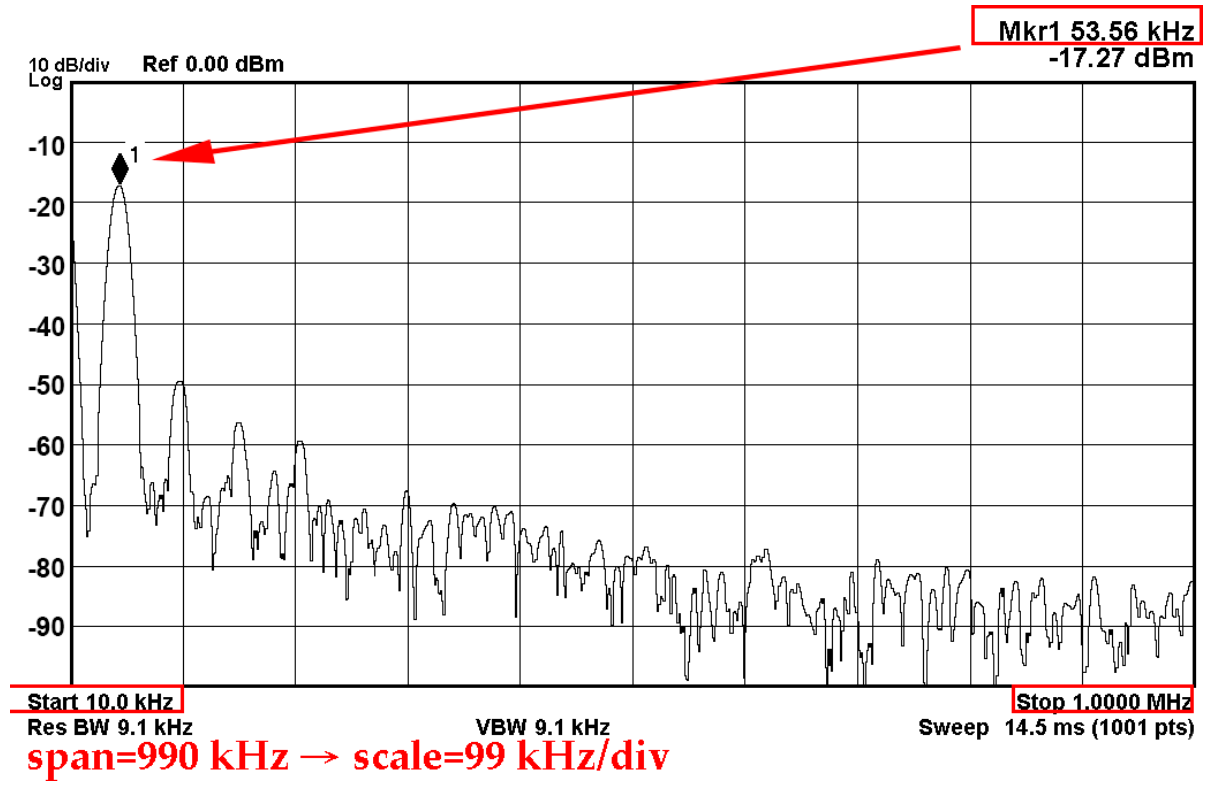

Figure 26. The measured frequency spectrum of the $\mathrm{V}_{\mathrm{o} 2}$ output terminal.

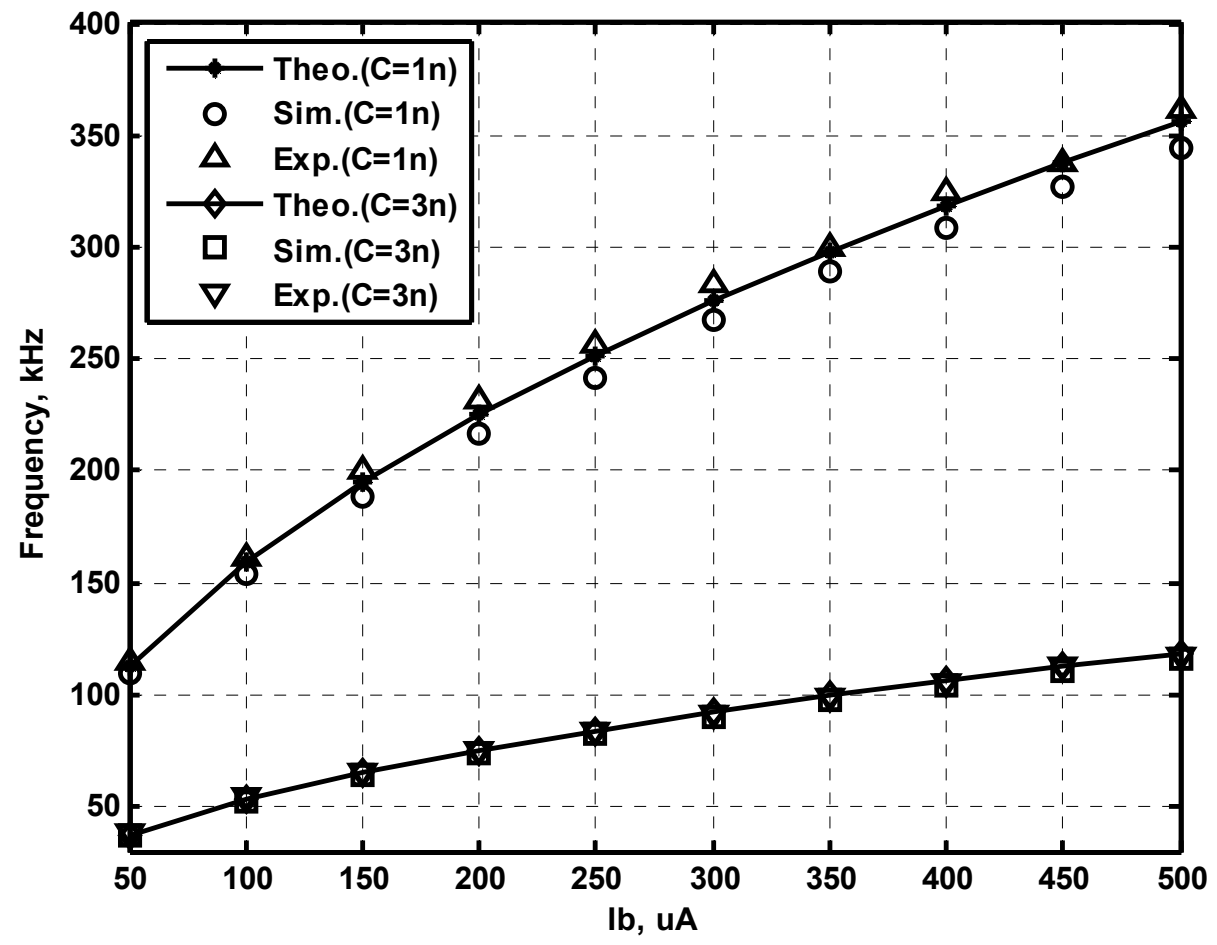

Figure 27. The frequency of oscillation (FO) theoretical, simulated and experimental results by varying the value of $g_{m 2}$. 


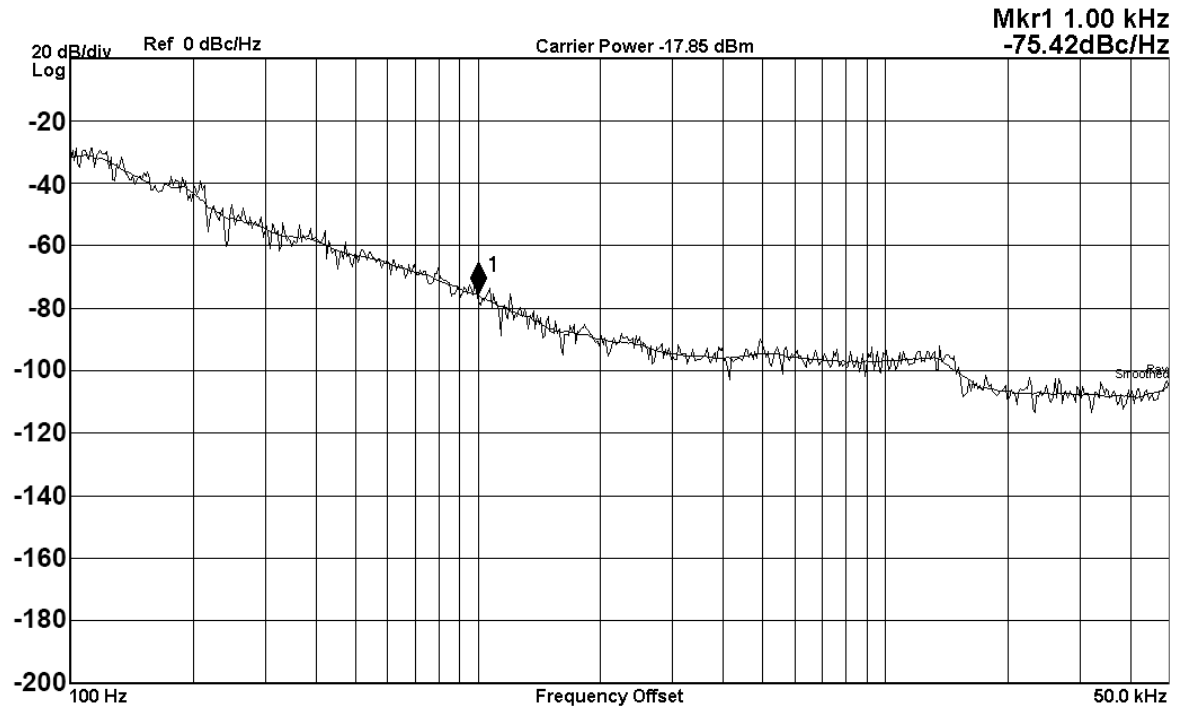

Figure 28. The measured phase noise of the VM quadrature oscillator at $1 \mathrm{kHz}$ offset.

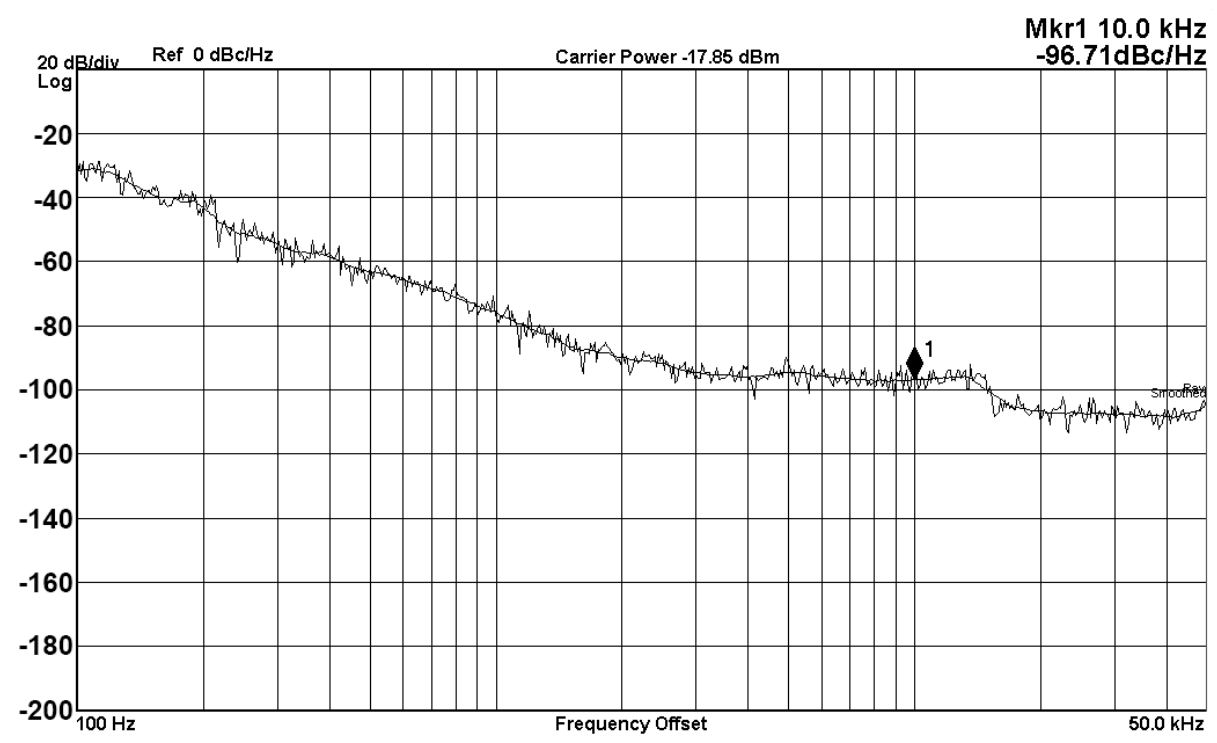

Figure 29. The measured phase noise of the VM quadrature oscillator at $10 \mathrm{kHz}$ offset.

Finally, the experimental test bench for the versatile VM biquadratic filter and quadrature oscillator is shown in Figure 30. In Figure 30, the experimental test bench includes a printed circuit board, a power supply, an oscilloscope, a network analyzer, and a signal analyzer. An oscilloscope is used to measure the time-domain of filter and oscillator waveforms. A network analyzer is used to measure the frequency-domain of the filter gain and phase responses. A signal analyzer is used to measure the frequency spectrum and analyze phase noise. Figures 31-40 show the filter measurement results of the network analyzer. In Figures 31-40, the authors have exported measurement data and added them as additional traces to Figures 7-16 in order to compare the theoretical analysis. 


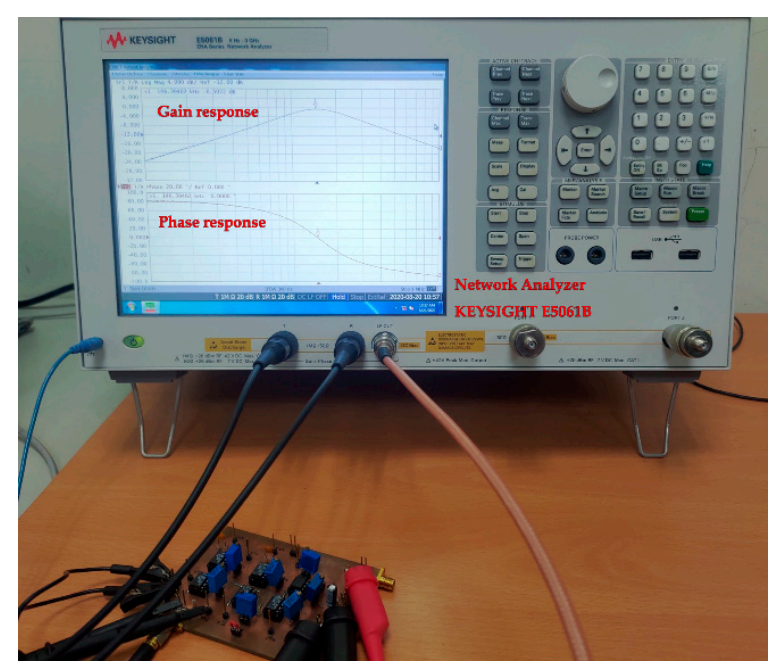

(a)

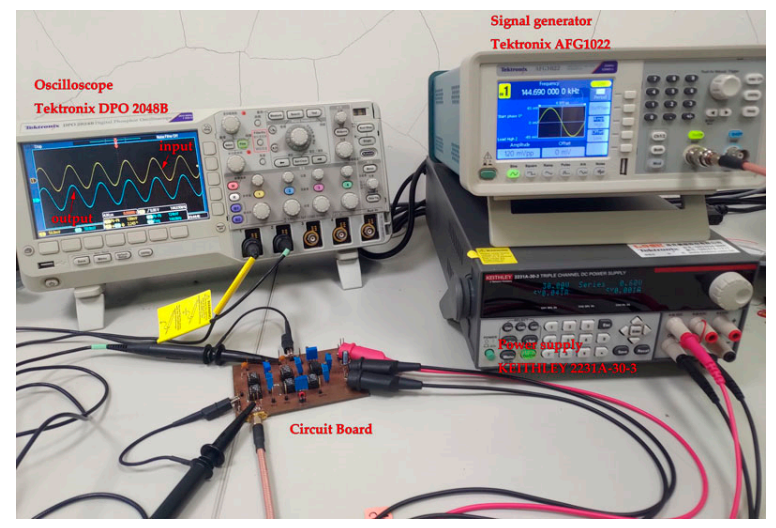

(b)

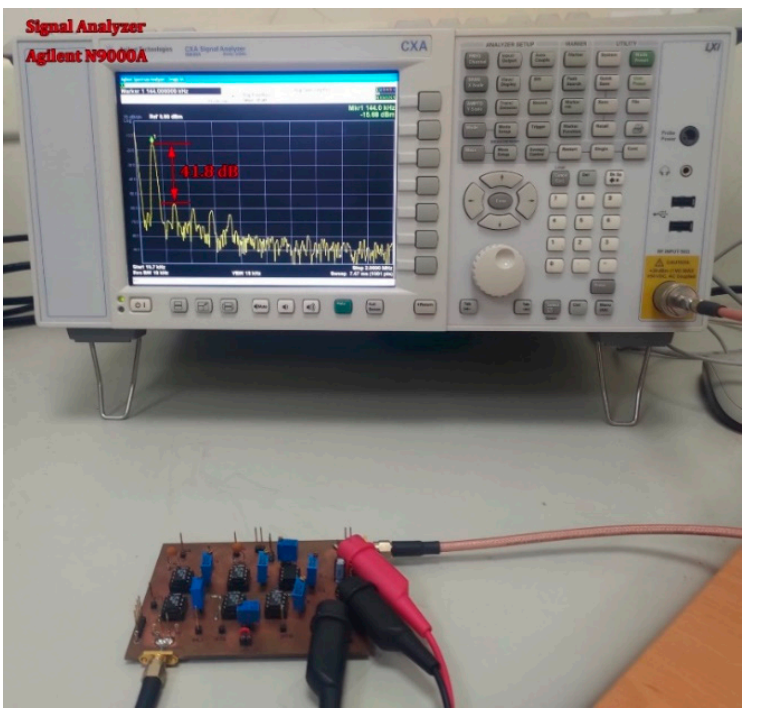

(c)

Figure 30. Cont. 


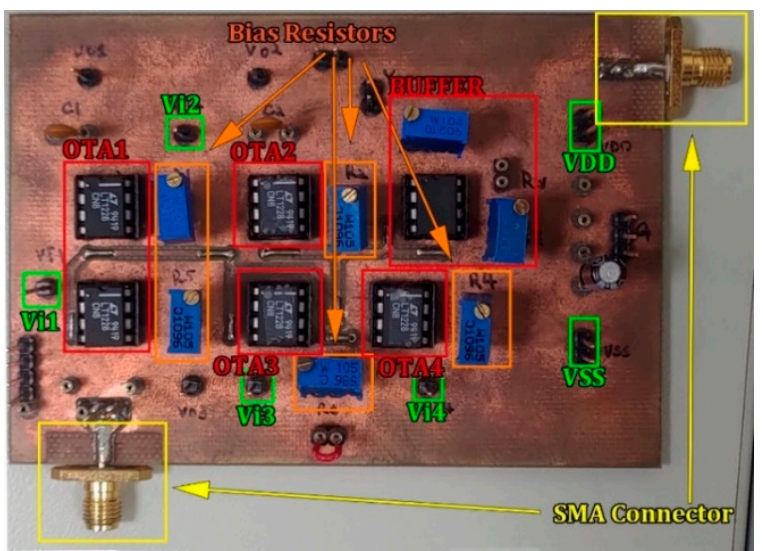

(d)

Figure 30. Experimental test bench for the versatile VM biquad filter and quadrature oscillator: (a) the measured gain and phase responses of the BP filter; (b) the measured time-domain of the BP filter in the center frequency of $144.69 \mathrm{kHz}$; (c) the measured frequency spectrum analysis of the BP filter of Figure 30b; and (d) the discrete element prototype board.

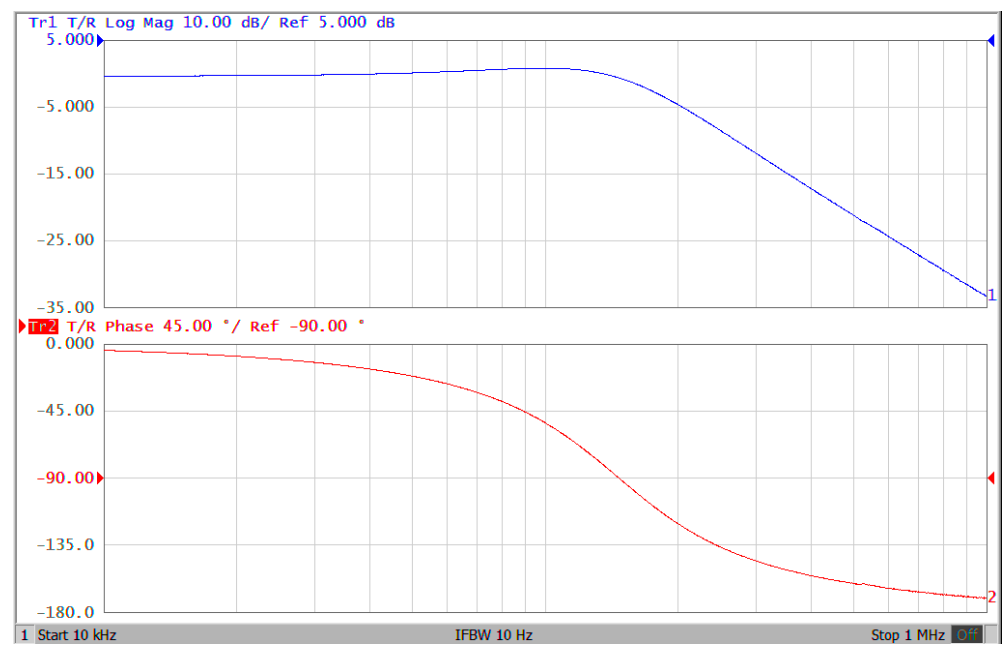

Figure 31. Experimentally observed gain and phase responses of the LP filter realized in case I.

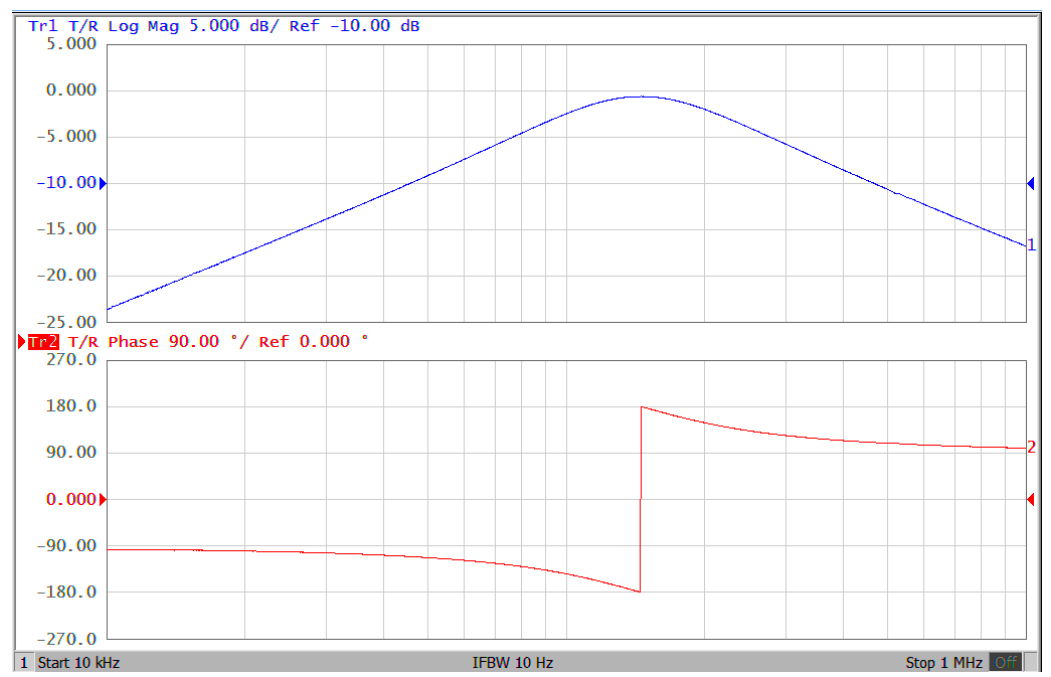

Figure 32. Experimentally observed gain and phase responses of the IBP filter realized in case I. 


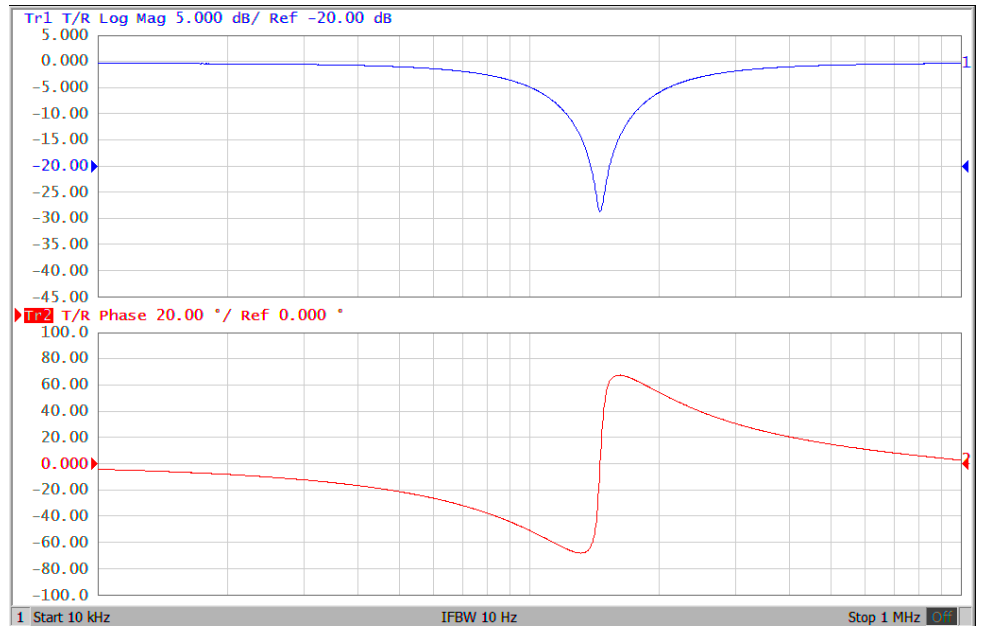

Figure 33. Experimentally observed gain and phase responses of the BR filter realized in case I.

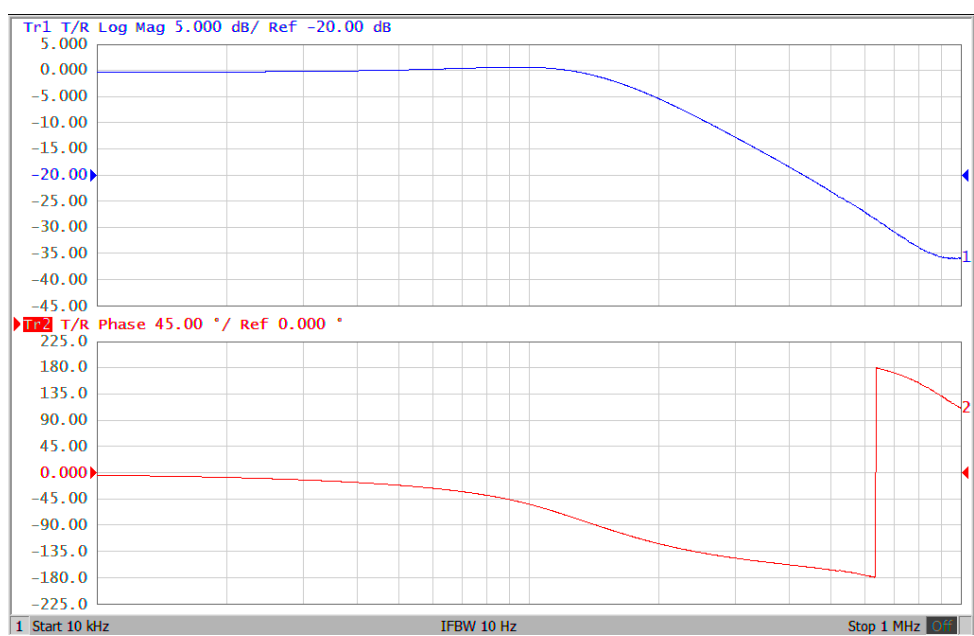

Figure 34. Experimentally observed gain and phase responses of the LP filter realized in case II.

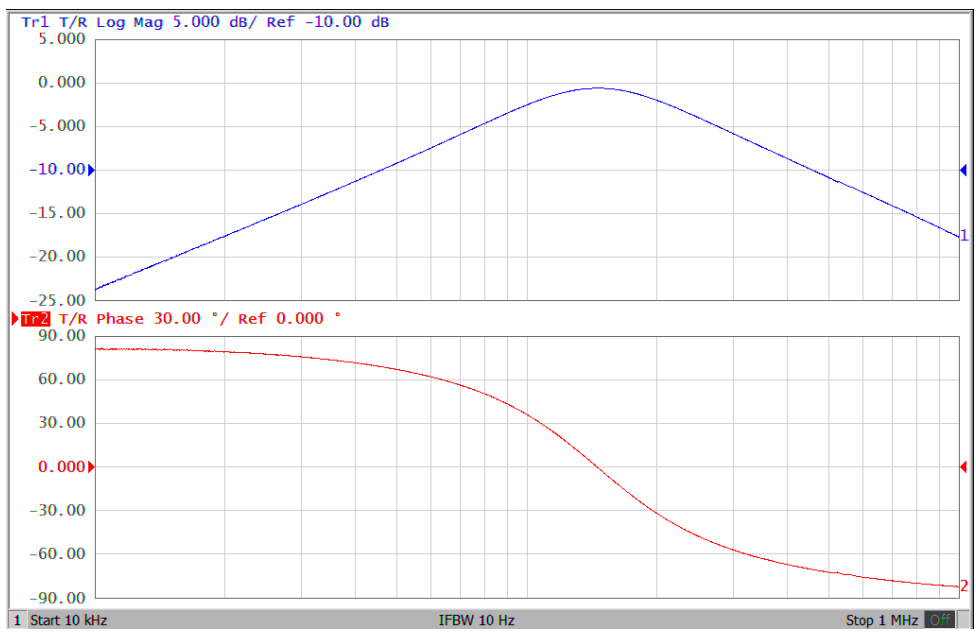

Figure 35. Experimentally observed gain and phase responses of the BP filter realized in case II. 


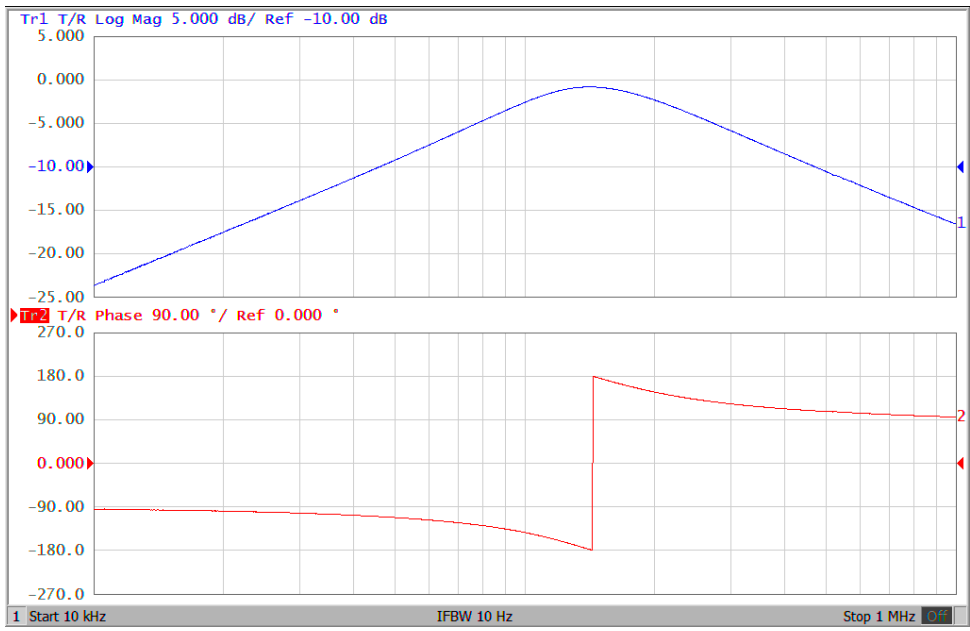

Figure 36. Experimentally observed gain and phase responses of the IBP filter realized in case II.

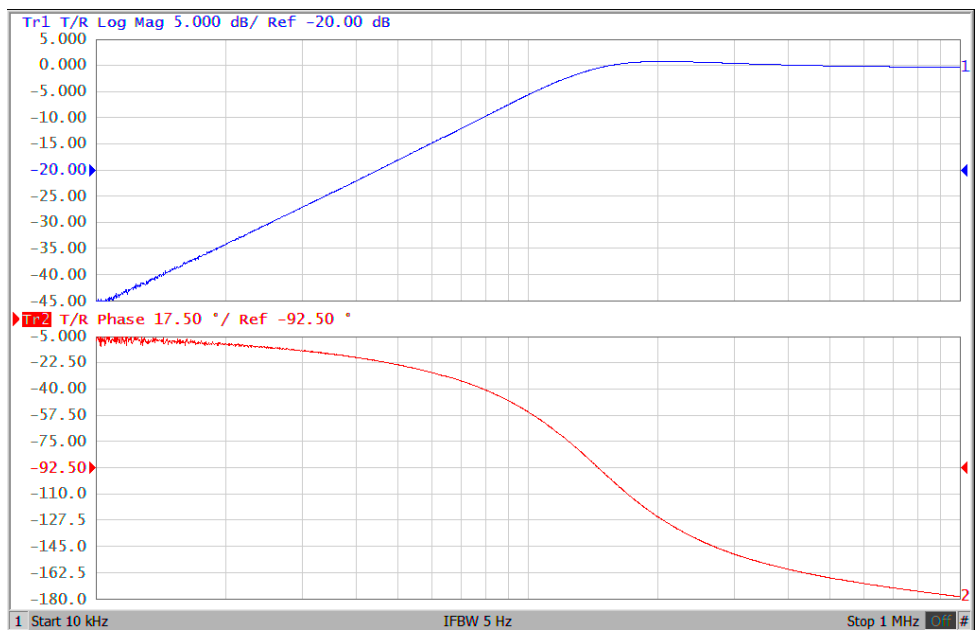

Figure 37. Experimentally observed gain and phase responses of the IHP filter realized in case II.

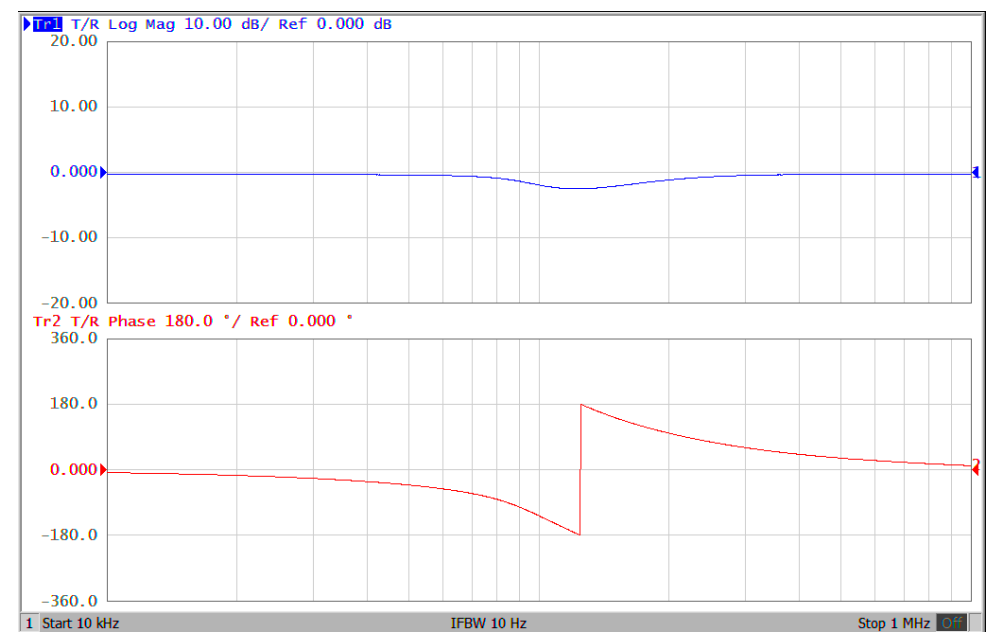

Figure 38. Experimentally observed gain and phase responses of the AP filter realized in case II. 


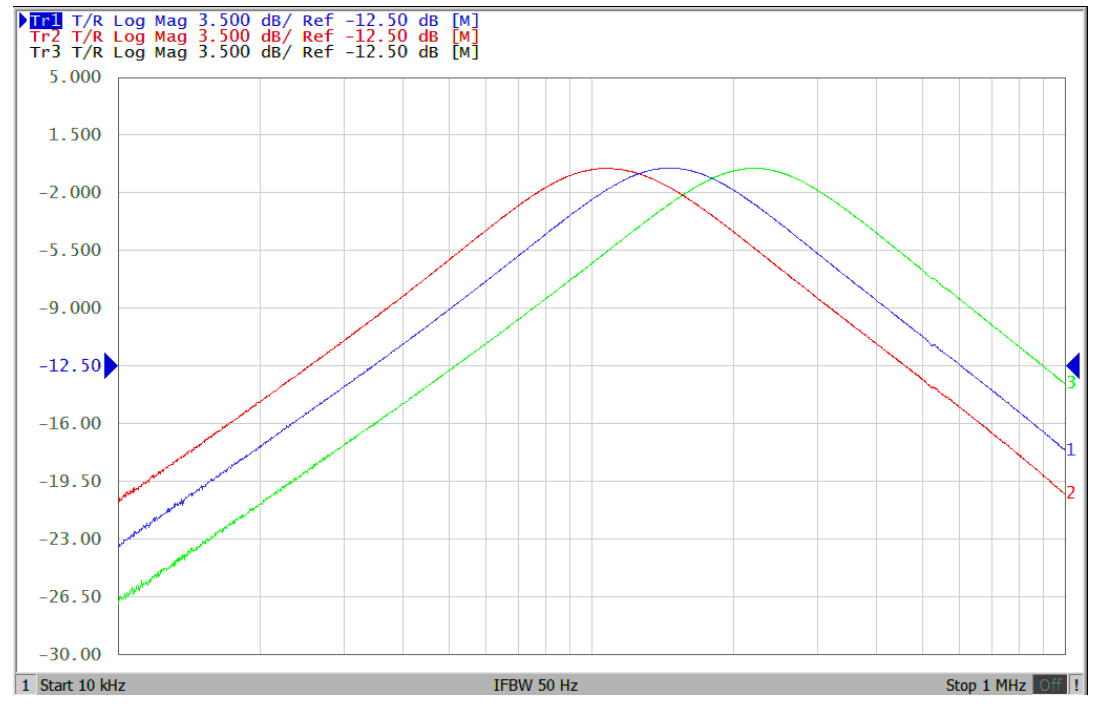

Figure 39. Experimentally observed gain responses of the BP filters realized by varying $\mathrm{f}_{\mathrm{O}}$ while keeping Q.

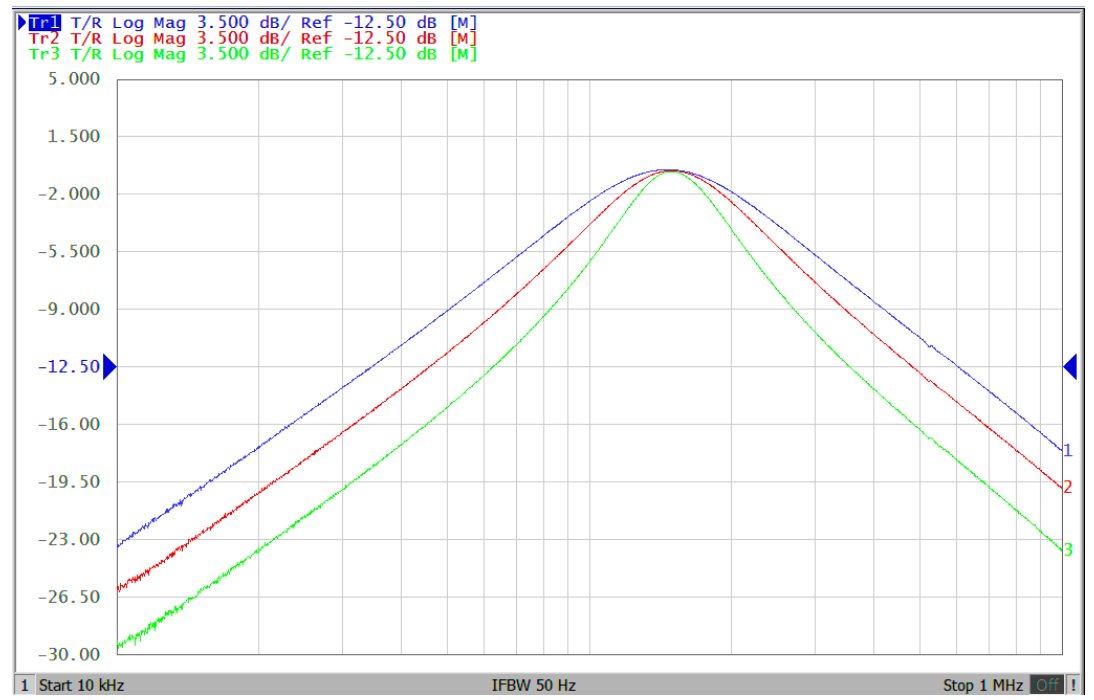

Figure 40. Experimentally observed gain responses of the BP filters realized by varying $\mathrm{Q}$ while keeping $f_{0}$.

\section{Conclusions}

In this paper, a configuration for realizing a versatile VM biquad filter with independent electronic tunability and a VM quadrature oscillator with the independent control of $\mathrm{CO}$ and FO using OTAs was presented. The proposed versatile VM biquad filter simultaneously exhibits BR, BP and LP filters by using one DO-OTA, three OTAs and two grounded capacitors. The proposed versatile VM biquad filter enjoys the following advantages: (i) four active components and two grounded capacitors are used, (ii) three basic filter responses with a single input and three outputs can be realized, (iii) LP, BP, IBP, HP, $\mathrm{BR}$ and AP filter responses can be realized by selecting different four input voltage signals, (iv) have multiple-input and multiple-output functions, (v) have independently and electronically controllable characteristic parameters $\omega_{\mathrm{o}}$ and $\mathrm{Q}$, (vi) all input terminals have cascade function, and (vii) there is no extra inverting amplifiers for special input signals. The proposed VM quadrature sinusoidal oscillator is based on the proposed VM biquad filter structure. The proposed VM quadrature oscillator provides two sinusoidal output voltages with a phase difference of $90^{\circ}$ and only uses grounded capacitors. $\mathrm{CO}$ and FO can be independently and electronically controlled. To the best knowledge of the authors, 
all these properties cannot be obtained simultaneously by any previously known OTA-based VM biquad filters. It must be emphasized that the proposed versatile VM biquad filter employs only four OTAs and two grounded capacitors, and its active component is one less than that of the recently proposed VM biquad filter in the open literature [47-49]. It also brings versatility and simplicity to the design of the VM biquad filter and VM quadrature oscillator. VM biquad filters and VM quadrature oscillators using less active and passive components have the advantages of low cost, low power dissipation, low circuit complexity, and low noise. The simulation and experimental results also confirm the theoretical analysis.

Author Contributions: S.-F.W. and H.-P.C. conceived and designed the theoretical verifications; the optimization ideas were provided by Y.K.; H.-P.C. analyzed the results and wrote the paper; C.-L.L. performed the simulations and experiments. All authors have read and agreed to the published version of the manuscript.

Funding: This research was funded by Ming Chi University of Technology.

Conflicts of Interest: The authors declare no conflict of interest.

\section{References}

1. Wang, H.Y.; Tran, H.D.; Nguyen, Q.M.; Yin, L.-T.; Liu, C.Y. Derivation of oscillators from biquadratic band pass filters using circuit transformations. Appl. Sci. 2014, 4, 482-492. [CrossRef]

2. Singh, V.K.; Singh, A.K.; Bhaskar, D.R.; Senani, R. New universal biquads employing CFOAs. IEEE Trans. Circuits Syst. II Express Briefs 2006, 53, 1299-1303. [CrossRef]

3. Márquez, A.; Pérez-Bailón, J.; Calvo, B.; Medrano, N.; Martínez, P.A. A CMOS self-contained quadrature signal generator for SoC impedance spectroscopy. Sensors 2018, 18, 1382. [CrossRef] [PubMed]

4. Ibrahim, M.A.; Minaei, S.; Kuntman, H.A. A $22.5 \mathrm{MHz}$ current-mode KHN-biquad using differential voltage current conveyor and grounded passive elements. AEU Int. J. Electron. Commun. 2005, 59, 311-318. [CrossRef]

5. Jaikla, W.; Adhan, S.; Suwanjan, P.; Kumngern, M. Current/voltage controlled quadrature sinusoidal oscillators for phase sensitive detection using commercially available IC. Sensors 2020, 20, 1319. [CrossRef]

6. Horng, J.W. High input impedance voltage-mode universal biquadratic filter using two OTAs and one CCII. Int. J. Electron. 2003, 90, 185-191. [CrossRef]

7. Horng, J.W.; Hsu, C.H.; Tseng, C.Y. High input impedance voltage-mode universal biquadratic filters with three inputs using three CCs and grounding capacitors. Radioengineering 2012, 21, 290-296.

8. Horng, J.W. Voltage-mode multifunction biquadratic filter employing single DVCC. Int. J. Electron. 2012, 99, 153-162. [CrossRef]

9. Chen, H.P.; Shen, S.S.; Wang, J.P. Electronically tunable versatile voltage-mode universal filter. AEU Int. J. Electron. Commun. 2008, 62, 316-319. [CrossRef]

10. Chen, H.P. Versatile multifunction universal voltage-mode biquadratic filter. AEU Int. J. Electron. Commun. 2010, 64, 983-987. [CrossRef]

11. Lee, C.N. Independently tunable plus-type DDCC-based voltage-mode universal biquad filter with MISO and SIMO types. Microelectron. J. 2017, 67, 71-81. [CrossRef]

12. Minaei, S.; Sayin, O.K.; Kuntman, H. A new CMOS electronically tunable current conveyor and its application to current-mode filters. IEEE Trans. Circuits Syst. I 2006, 53, 1448-1457. [CrossRef]

13. Masud, M.; A'ain, A.; Khan, I.; Husin, N. Design of voltage mode electronically tunable first order all pass filter in $\pm 0.7 \mathrm{~V} 16 \mathrm{~nm}$ CNFET Technology. Electronics 2019, 8, 95. [CrossRef]

14. Zhang, C.; Shang, L.; Wang, Y.; Tang, L. A CMOS programmable fourth-order butterworth active-RC low-pass filter. Electronics 2020, 9, 204. [CrossRef]

15. Acosta, L.; Jimenez, M.; Carvajal, R.G.; Lopez-Martin, A.J.; Ramirez-Angulo, J. Highly linear tunable CMOS gm-C low-pass filter. IEEE Trans. Circuits Syst. I Regul. Pap. 2009, 56, 2145-2158. [CrossRef]

16. Acar, C.; Naday, F.; Kuntman, H. On the realization of OTA-C filter. Int. J. Circuit Appl. 1993, 21, 331-341. [CrossRef]

17. Chang, C.M.; Soliman, A.M.; Swamy, M.N.S. Analytical synthesis of low-sensitivity high-order voltage-mode DDCC and FDCCII-grounded R and C all-pass filter structures. IEEE Trans. Circuits Syst. I Regul. Pap. 2007, 54, 1430-1443. [CrossRef] 
18. Hwang, Y.S.; Kung, C.M.; Lin, H.C.; Chen, J.J. Low-sensitivity, low-bounce, high-linearity current-controlled oscillator suitable for single-supply mixed-mode instrumentation system. IEEE Trans. Ultrason. Ferroelectr. Freq. Control 2009, 56, 254-262. [CrossRef]

19. Hwang, Y.S.; Liu, W.H.; Tu, S.H.; Chen, J.J. New building block: Multiplication-mode current conveyor. IET Circuits Devices Syst. 2009, 3, 41-48. [CrossRef]

20. Tu, S.H.; Hwang, Y.S.; Chen, J.J.; Soliman, A.M.; Chang, C.M. OTA-C arbitrary-phase-shift oscillators. IEEE Trans. Instrum. Meas. 2012, 61, 2305-2319. [CrossRef]

21. Nikoofard, A.; Kananian, S.; Fotowat-Ahmady, A. Off-resonance oscillation, phase retention, and orthogonality modeling in quadrature oscillators. IEEE Trans. Circuits Syst. I Regul. Pap. 2016, 3, 883-894. [CrossRef]

22. Chang, C.M.; Tu, S.H.; Swamy, M.N.S.; Soliman, A.M. Analytical synthesis of elliptic voltage-mode even/odd-nth-order filter structures using DDCCs, FDCCIIs, and grounded capacitors and resistors. IET Circuits Devices Syst. 2019, 13, 279-291. [CrossRef]

23. Abuelma'atti, M.T.; Farooqi, A.A.; Alshahrani, S.M. Novel RC oscillators using the current-feedback operational amplifier. IEEE Trans. Circuits Syst. I Fundam. Theory Appl. 1996, 43, 155-157. [CrossRef]

24. Liu, S.I.; Wu, D.S. New current-feedback amplifier-based universal biquadratic filter. IEEE Trans. Instrum. Meas. 1995, 44, 915-917.

25. Hornng, J.W. New configuration for realizing universal voltage-mode filter using two current-feedback amplifiers. IEEE Trans. Instrum. Meas. 2000, 49, 1043-1045. [CrossRef]

26. Yuce, E.; Minaei, S. A modified CFOA and its applications to simulated inductors, capacitance multipliers, and analog filters. IEEE Trans. Circuits Syst. I Regul. Pap. 2008, 55, 266-275. [CrossRef]

27. Singh, A.K.; Senani, R. Active-R design using CFOA-poles: New resonators, filters, and oscillators. IEEE Trans. Circuits Syst. I Analog Digit. Sig. Process. 2001, 48, 504-511. [CrossRef]

28. Tao, Y.; Fidler, J.K. Electronically tunable dual-OTA second-order sinusoidal oscillators/filters with non-interacting controls: A systematic synthesis approach. IEEE Trans. Circuits Syst. I Fundam. Theory Appl. 2000, 47, 117-129.

29. Tran, H.D.; Wang, H.Y.; Lin, M.C.; Nguyen, Q.M. Synthesis of cascadable DDCC-based universal filter using NAM. Appl. Sci. 2015, 5, 320-343. [CrossRef]

30. Herencsar, N.; Koton, J.; Hanak, P. Universal voltage conveyor and its novel dual-output fully-cascadable VM APF application. Appl. Sci. 2017, 7, 307. [CrossRef]

31. Sotner, R.; Jerabek, J.; Langhammer, L.; Dvorak, J. Design and analysis of CCII-based oscillator with amplitude stabilization employing optocouplers for linear voltage control of the output frequency. Electronics 2018, 7, 157. [CrossRef]

32. Ullah, F.; Liu, Y.; Li, Z.; Wang, X.; Sarfraz, M.M.; Zhang, H. A bandwidth-enhanced differential LC-voltage controlled oscillator (LC-VCO) and superharmonic coupled quadrature VCO for K-band applications. Electronics 2018, 7, 127. [CrossRef]

33. Safari, L.; Barile, G.; Ferri, G.; Stornelli, V. A new low-voltage low-power dual-mode VCII-based SIMO universal filter. Electronics 2019, 8, 765. [CrossRef]

34. Horng, J.W. Voltage-mode universal biquadratic filter using two OTAs. Act. Passiv. Electron. Comp. 2004, 27, 85-89. [CrossRef]

35. Kumar, K.; Pal, K. Voltage mode multifunction OTA-C biquad filter. Microelectron. Int. 2006, $23,24-27$. [CrossRef]

36. Shan, N.A.; Rather, M.F. Voltage-mode OTA-based active-C universal filter and its transformation into CFA-based RC-filter. Indian J. Pure Appl. Phys. 2006, 44, 402-406.

37. Singh, G.; Bhaskar, D.R.; Prasad, D. Three-input one-output voltage-mode MISO-Type biquad using OTAs. Int. J. Electron. Electron. Comput. Syst. 2015, 4, 342-347.

38. Kumngern, M.; Suwanjan, P.; Dejhan, K. Electronically tunable voltage-mode universal filter with single-input five-output using simple OTAs. Int. J. Electron. 2013, 100, 1118-1133. [CrossRef]

39. Lee, C.N. Versatile transadmittance-mode OTA-C universal biquad filter using minimum components with independently electronic tunability. J. Circuits Syst. Comput. 2014, 23, 1450102. [CrossRef]

40. Bhaskar, D.R.; Raj, A.; Kumar, P. Mixed-mode universal biquad filter using OTAs. J. Circuits Syst. Comput. 2020, 29, 2050162. [CrossRef] 
41. Chiu, W.Y.; Horng, J.W. High-input and low-output impedance voltage-mode universal biquadratic filter using DDCCs. IEEE Trans. Circuits Syst. II Express Briefs 2007, 54, 649-652. [CrossRef]

42. Tsukutani, T.; Higashimura, M.; Sumi, Y.; Fukui, Y. Voltage-mode active-only biquad. Int. J. Electron. 2000, 20, 1435-1442. [CrossRef]

43. Chang, C.M. Analytical synthesis of the digitally programmable voltage-mode OTA-C universal biquad. IEEE Trans. Circuits Syst. II Express Briefs 2006, 53, 607-611. [CrossRef]

44. Kumngern, M.; Knobnob, B.; Dejhan, K. Electronically tunable high-input impedance voltage-mode universal biquadratic filter based on simple CMOS OTAs. AEU Int. J. Electron. Commun. 2010, 64, 934-939. [CrossRef]

45. Kumngern, M.; Suksaibul, P.; Khateb, F. Four-input one-output voltage-mode universal filter using simple OTAs. J. Circuits Sys. Comp. 2019, 28, 1950078. [CrossRef]

46. Psychalinos, C.; Kasimis, C.; Khateb, F. Multiple-input single-output universal biquad filter using single output operational transconductance amplifiers. AEU Int. J. Electron. Commun. 2018, 93, 360-367. [CrossRef]

47. Wang, S.F.; Chen, H.P.; Ku, Y.; Yang, C.M. A voltage-mode universal filter using five single-ended OTAs with two grounded capacitors and a quadrature oscillator using the voltage-mode universal filter. Optik 2019, 192, 162950. [CrossRef]

48. Wang, S.F.; Chen, H.P.; Ku, Y.; Lin, Y.C. Versatile tunable voltage-mode biquadratic filter and its application in quadrature oscillator. Sensors 2019, 19, 2349. [CrossRef]

49. Wang, S.F.; Chen, H.P.; Ku, Y.; Yang, C.M. Independently tunable voltage-mode OTA-C biquadratic filter with five inputs and three outputs and its fully-uncoupled quadrature sinusoidal oscillator application. AEU Int. J. Electron. Commun. 2019, 100, 152822. [CrossRef]

50. LT1228-100 MHz Current Feedback Amplifier with DC Gain Control, Linear Technology Corporation Version Number D. 2012. Available online: http://www.linear.com/product/LT1228 (accessed on 1 October 2019).

(C) 2020 by the authors. Licensee MDPI, Basel, Switzerland. This article is an open access article distributed under the terms and conditions of the Creative Commons Attribution (CC BY) license (http://creativecommons.org/licenses/by/4.0/). 